Document downloaded from:

http://hdl.handle.net/10251/137594

This paper must be cited as:

Squicciarini, G.; Thompson, D.; Ding, B.; Baeza González, LM. (2018). A state-of-the-art review of curve squeal noise: Phenomena, mechanisms, modelling and mitigation. Notes on Numerical Fluid Mechanics and Multidisciplinary Design. 139:3-41. https://doi.org/10.1007/978-3-319-73411-8_1

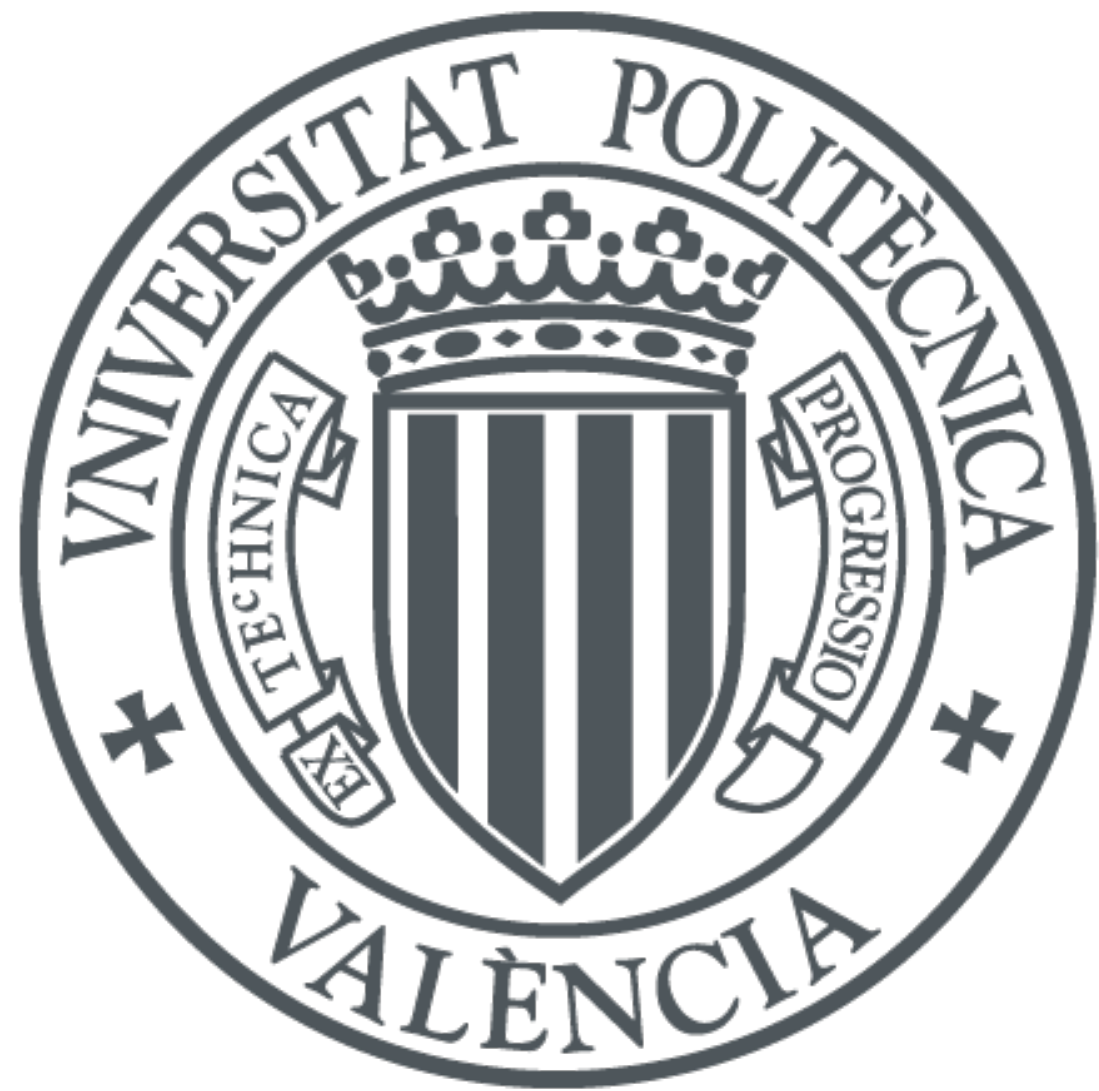

The final publication is available at

https://doi.org/10.1007/978-3-319-73411-8_1

Copyright Springer

Additional Information 


\title{
A state-of-the-art review of curve squeal noise: phenomena, mechanisms, modelling and mitigation
}

\author{
D.J. Thompson ${ }^{1}$, G. Squicciarini ${ }^{1}$, B. Ding ${ }^{1}$ and L. Baeza $^{1}$ \\ ${ }^{1}$ Institute of Sound and Vibration Research, \\ University of Southampton, Southampton SO17 1BJ, UK \\ Tel: +44 238059 2510, Fax: +44 238059 3190, E-mail: djt@isvr.soton.ac.uk
}

\begin{abstract}
Summary
Curve squeal is an intense tonal noise occurring when a rail vehicle negotiates a sharp curve. The phenomenon can be considered to be chaotic, with a widely differing likelihood of occurrence on different days or even times of day. The term curve squeal may include several different phenomena with a wide range of dominant frequencies and potentially different excitation mechanisms. This review addresses the different squeal phenomena and the approaches used to model squeal noise; both time-domain and frequency-domain approaches are discussed and compared. Supporting measurements using test rigs and field tests are also summarised. A particular aspect that is addressed is the excitation mechanism. Two mechanisms have mainly been considered in previous publications. In many early papers the squeal was supposed to be generated by the so-called falling friction characteristic in which the friction coefficient reduces with increasing sliding velocity. More recently the mode coupling mechanism has been raised as an alternative. These two mechanisms are explained and compared and the evidence for each is discussed. Finally, a short review is given of mitigation measures and some suggestions are offered for why these are not always successful.
\end{abstract}

\section{Introduction}

Curve squeal is an intense tonal noise produced when railway vehicles negotiate sharp curves. It is probably the most annoying type of noise produced by the railway system due to its tonal nature and its high noise levels. It is also highly unpredictable, with a widely differing likelihood of occurrence for nominally identical vehicles, or for same vehicles on different days or even times of day and might be considered to be chaotic rather than deterministic. Anderson et al. [1] indicate that curve squeal is one of the Australian rail industry's top noise mitigation priorities. Moreover, Hanson et al. [2] point out that squeal noise can be seen as a symptom of the deterioration of some aspect of the maintenance or operation of the railway system: insufficient lubrication leading to wear as well as noise; poor rail profiles leading to high stresses; or poorly steering rolling stock leading to increased wear and fuel consumption.

This paper provides a review of curving noise phenomena, mechanisms, models and mitigation measures. The term curve squeal (or screech) may be used to include several different phenomena with a wide range of dominant frequencies and potentially with different excitation mechanisms. Some authors have made a distinction between 'curve squeal', in which the noise is strongly tonal, and the more intermittent, higher frequency noise that is sometimes called 'flanging noise'. Despite this naming convention there is little conclusive evidence that the latter is actually associated with contact at the wheel flange. Rail corrugation can also occur in curves and lead to high noise levels which may be mistaken for curving noise.

Curve squeal is usually associated with the wider field of friction-induced vibration, a field that includes the classic example of the excitation of the violin string by the bow, some forms of tyre/road noise and brake squeal. Rudd [3] described three alternative mechanisms but concluded that the unsteady lateral creepage at the wheel/rail contact is the most likely reason to induce squeal noise. According to Rudd, the falling friction mechanism (described in Section 2) leads to unstable vibration of a mode of the wheel; this will grow in 
amplitude until the non-linearities in the creep forces result in a limit cycle. He also suggested that rail vibration can be neglected in comparison with the vibration of wheel. Rudd's model was also described by Remington at IWRN4 in a review that covered squeal and impact noise [4] as well as rolling noise [5].

The model of Rudd [3], based on the concept of 'falling friction', has formed the basis of many subsequent and more detailed models of curve squeal. However, more recently a number of authors have proposed an alternative mechanism based on 'mode coupling'. The purpose of this paper is to explain these two mechanisms, to review experimental and theoretical work in the field of curve squeal and to discuss mitigation measures in terms of these two mechanisms. The mechanisms are introduced and compared in Section 2 on the basis of simple models. Models of curve squeal are reviewed in Section 3, measurements on test rigs and in the field are described in Section 4 and mitigation measures are discussed in Section 5.

\section{Frictional excitation}

\subsection{Curving behaviour}

Curve squeal can be attributed to 'imperfect' curving behaviour of railway vehicles. The coned wheelset naturally steers around a curve by aligning itself radially to the curve and moving outwards so that the rolling radius difference between the wheels compensates for the different distances travelled. However, for a bogie (or a two-axle vehicle) the yaw stiffness between the axles and the frame, required to ensure stable running at high speed, prevents the axles from orientating themselves fully radially [6]. Consequently, the wheelsets have a nonzero angle of attack. On sharp curves the leading wheelset of a bogie tends to run in flange contact at the outer wheel whereas the trailing wheelset may run in flange contact at the inner wheel; at higher speeds it moves outwards. The angle of attack is greatest at the leading wheelset, as shown schematically in Figure 1(a).

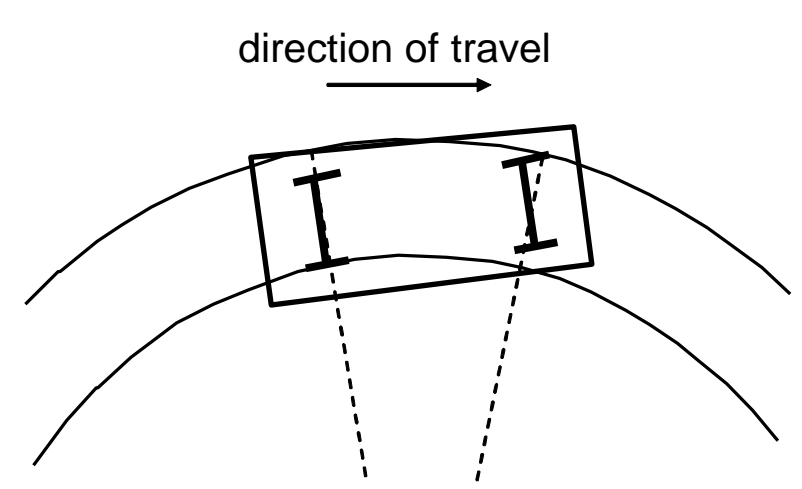

(a)

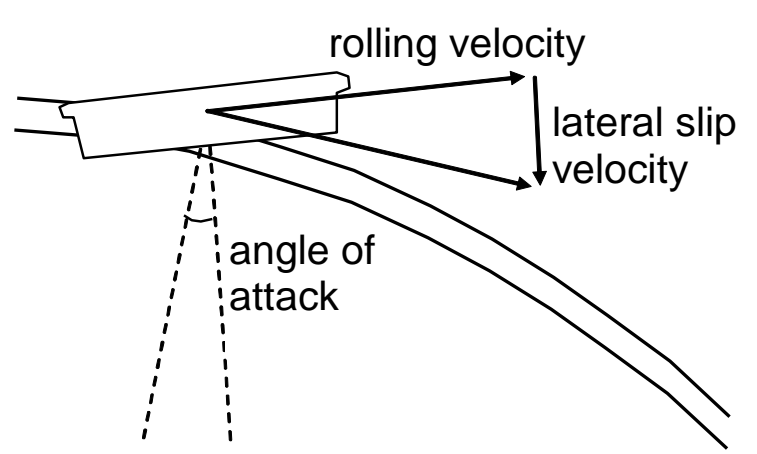

(b)

Figure 1. (a) Typical curving behaviour for small radius curve showing that the leading wheelset has a large angle of attack; (b) generation of lateral creepage by a non-zero angle of attack [7].

Due to the non-zero angle of attack, there is a small lateral relative velocity between the wheel and the rail, see Figure 1(b). The relative velocity normalised by the rolling velocity is known as the creepage; components in the longitudinal and spin (rotation about the normal) directions also exist. The lateral creepage is approximately equal to the angle of attack. The creepages give rise to reaction forces known as creep forces. At low values of creepage, the creep force increases linearly with increasing creepage [8]. However, at large values of creepage, such as occurring in sharp curves, the creep force 'saturates' and takes the value of the Coulomb friction coefficient multiplied by the normal load. The ratio of the creep force to the normal load will be referred to here as the adhesion coefficient; in the saturated region it is identical to the friction coefficient. Models for the creep behaviour have been developed by Kalker [8] including the approximate method FASTSIM and the fuller method CONTACT. Vermeulen \& Johnson [9] and Shen et al. [10] also give approximate methods.

The importance of friction behaviour on the excitation of squeal noise is widely recognised. To illustrate this, and the basic mechanisms behind it, simple systems are considered in the next sections consisting of a single mode of vibration or a pair of modes. 


\subsection{Simple models of oscillators with friction}

A simple model that can be used to illustrate stick-slip mechanisms is a mass on a belt moving at velocity $V_{0}$, as shown in Figure 2. The mass $m$ is restrained by a spring of stiffness $k$ and damper $c$ and held against the belt by a constant normal load $N$. This model can be used to represent a wheel vibrating in a single natural mode (although a wheel has many modes, the squeal response is usually dominated by a single mode). The sliding velocity between the mass and the belt represents the lateral creep velocity (not the rolling velocity), which has a steady-state value of $V_{0}$.

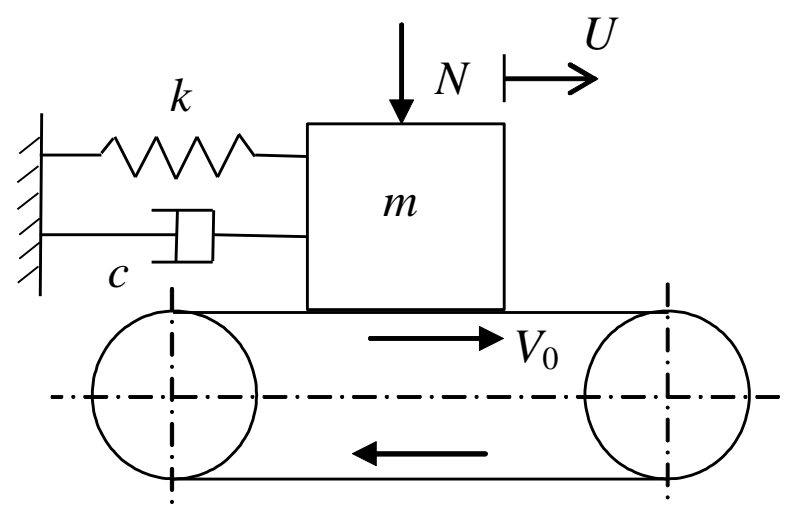

Figure 2. Schematic view of a restrained mass on a moving belt.

In this section we consider friction to be represented by a static coefficient $\mu_{s}$ (when there is no relative motion) and a dynamic coefficient $\mu_{d}$ (when there is slip), with $\mu_{s}>\mu_{d}$. In the stick phase the mass moves at the same velocity as the belt and the friction force $F$ satisfies $|F|<\mu_{s} N$. As the mass moves, the spring is extended until the spring force exceeds the friction limit and sliding commences. The equation of motion for this system satisfies two different conditions, one for the stick phase of the mechanism and one for the slip phase:

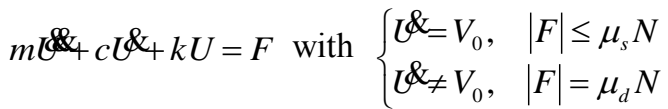

where $U$ represents the vibration displacement. During sliding, according to the second equation, the mass undergoes harmonic motion at the natural frequency $\omega_{0}=\sqrt{\mathrm{k} / \mathrm{m}}$. However, due to the existence of the stick phase, the period of oscillation is longer than the natural period associated with the mass-spring system. As shown in [7] the relative importance of the stick and slip phases depends on a non-dimensional parameter

$$
\beta=\left(\mu_{s}-\mu_{d}\right) \frac{N}{V_{0} m \omega_{0}}
$$

For curve squeal situations the value of $\beta$ is usually in the range 0.1 to 1 [7]. Figure 3(a) show examples of the stick-slip motion for three values of $\beta$. These are shown in the 'phase plane' in which the velocity is plotted against the displacement. Here, the velocity is normalised by the belt velocity $V_{0}$ whereas the displacement is normalised by $V_{0} / \omega_{0}$. These results illustrate the formation of a 'limit cycle': a stable periodic motion that is reached from a variety of initial conditions. It is found that, for small values of $\beta$ the slip phase predominates, the motion is close to elliptical on the phase plane and the oscillation frequency is close to the natural frequency, whereas for large values of $\beta$ the stick phase predominates and the oscillation frequency is lower than the natural frequency [7]. Moreover, as the motion is not purely sinusoidal due to the nonlinearity of the friction model, its spectrum will contain higher harmonics in addition to the fundamental frequency, a feature often seen in squeal measurements.

Using this simple model also allows the effect of damping to be assessed. Figure 3(b) shows results for $\beta=1$ for three values of damping ratio. As the damping is increased, this has only a small effect on the amplitude of the limit cycle until the damping reaches a value where the oscillations are suppressed; in this case for $\zeta=0.1$ the damping exceeds the limiting value and the oscillations decay. The limiting value of damping ratio can be approximated as $\zeta>\beta^{2} / 4 \pi$ [7]. 


\subsection{Negative friction slope model}

As will be seen, the friction coefficient is often found to fall with increasing sliding velocity. The slope of the relation between force and velocity corresponds to a damper (the force due to a damper is proportional to the relative velocity) so a force which falls in magnitude with increasing relative velocity corresponds to a negative damper. If there is a greater negative damping than the positive damping inherent in the oscillator, unstable selfexcited vibration occurs [3], the amplitude of which grows exponentially. In reality, the amplitude is then limited by non-linear effects in the creep force, as there is a region with positive slope close to the origin of the force-creepage relation, see Figure 4(a).

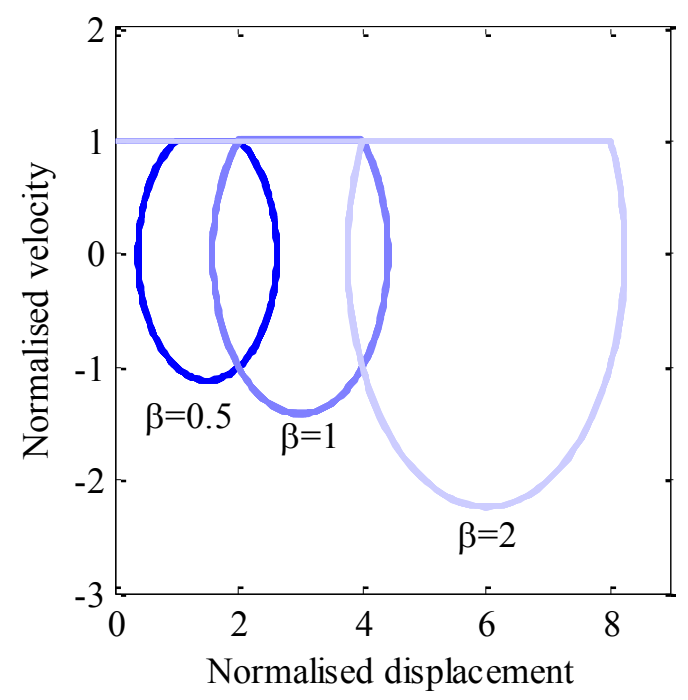

(a)

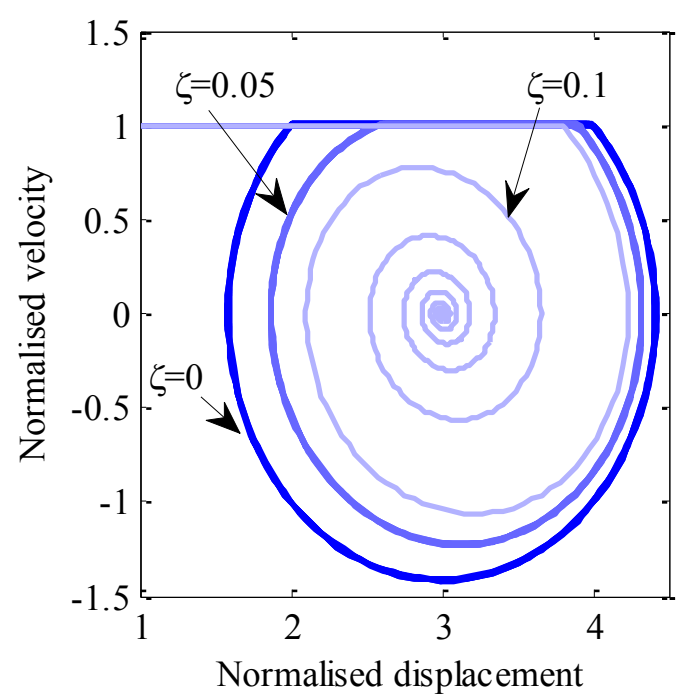

(b)

Figure 3. Normalised displacement vs non-dimensional velocity of a simplified stick-slip mechanism: $\mu_{s}=0.4, \mu_{d}=0.3$. (a) without damping; (b) for different damping levels $(\beta=1)$.

To illustrate this, the single-degree-of-freedom system of the mass on moving belt can still be adopted to simulate the self-excited vibration of a single wheel mode. Eliminating the steady-state component of the displacement and force, the equation of motion of the system takes the form:

$$
2 \zeta \omega_{0} \iota \&+\omega_{0}^{2} u=-\frac{N}{m}\left(\left.\mu\right|_{\gamma_{0}+\gamma}-\left.\mu\right|_{\gamma_{0}}\right)
$$

where $u=U-U_{0}$ is the dynamic component of the vibration displacement ( $U_{0}$ is the displacement of the belt moving at speed $V_{0}$ ), $\zeta$ is the damping ratio, $\omega_{0}$ is the natural frequency, $N$ is the load normal to the contact plane, $m$ is the mass, $\mu$ is the adhesion coefficient (creep force normalised by the normal load), $\gamma_{0}$ is the lateral creepage at steady state and $\gamma=\iota \& V$ is its dynamic component. The right-hand side represents the dynamic component of creep force (normalised by the mass).

For small variations in creepage, the right-hand side of equation (2.3) can be linearized:

$$
2 \zeta \omega_{0} \iota \&+\omega_{0}^{2} u=-\left.\frac{N}{m V} \frac{\mathrm{d} \mu}{\mathrm{d} \gamma}\right|_{\gamma_{0}} \&
$$

This can be identified as a damping term corresponding to the creep force, which can be compared with the structural damping as a check for stability. Thus if the damping ratio is smaller than

$$
\zeta_{\text {lim }}=-\left.\frac{N}{2 m \omega_{0} V} \frac{\mathrm{d} \mu}{\mathrm{d} \gamma}\right|_{\gamma_{0}}
$$


the system will be unstable and the vibration will grow, whereas for larger values of damping the oscillation will decay. Meanwhile, the solution of the non-linear equation (2.3) gives the limit cycle.

The parameters given in Table 1 are adopted in an illustrative simulation and, although arbitrary, they are plausible for a railway wheel. The simplified creep force model proposed by Vermeulen and Johnson [9] is adopted with a falling part as proposed by Huang [11] (see also Section 4.1.2). Figure 4(a) shows the creep force normalised by the normal load (referred to as the adhesion coefficient). Also shown is the corresponding curve obtained with constant friction coefficient of 0.4. The steady-state creepage is chosen as 0.005 . The solution for the undamped system with falling friction is shown in Figure 4(b); the solution grows exponentially until the creepage falls below 0.0018, which corresponds to the value where the slope in Figure 4(a) changes sign. For values below this (indicated by the horizontal line in Figure 4(b)) the creep force tends to stabilise the system. The limit cycle is reached when the energy fed into the system during the portion of the period corresponding to a falling creep force (overall negative damping) equals the energy dissipated during the time spent in the region with force increasing with creepage (overall positive damping). Clearly, in a situation like this, instability can be avoided by increasing the structural damping above the limit value given in equation (2.5). For constant friction there is no instability of this system. According to this model the instability is also independent of the level of static friction.

Table 1. Parameters of a single mode of the wheel

\begin{tabular}{|c|c|c|c|}
\hline Modal mass & $156 \mathrm{~kg}$ & Steady-state creepage, $\gamma_{0}$ & 0.005 \\
\hline Natural frequency, $\omega_{0} / 2 \pi$ & $1003 \mathrm{~Hz}$ & Rolling velocity, $V$ & $10 \mathrm{~m} / \mathrm{s}$ \\
\hline Normal contact force, $N$ & $42 \mathrm{kN}$ & Damping ratio & 0 \\
\hline
\end{tabular}

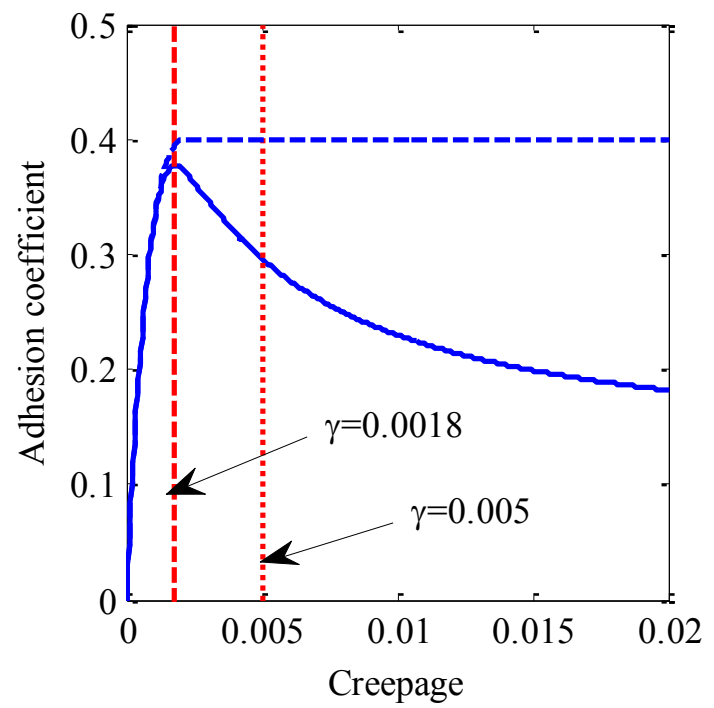

(a)

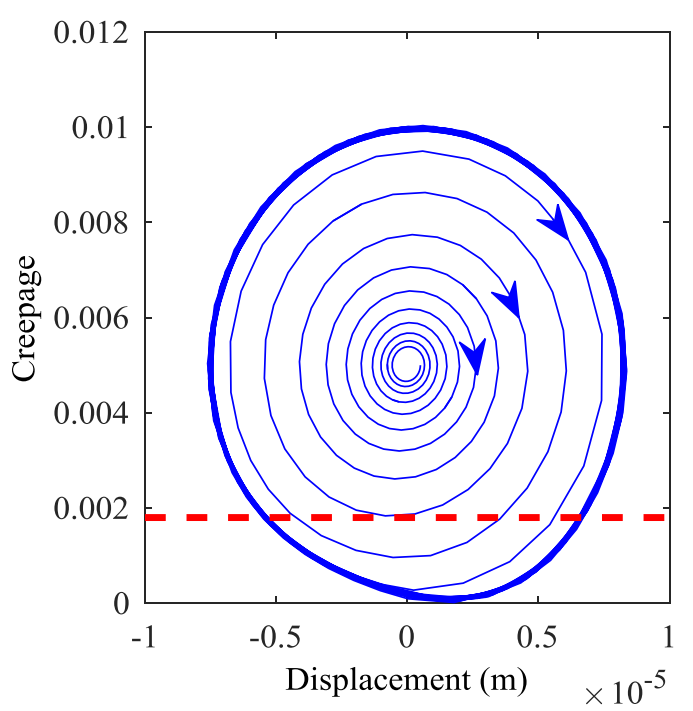

(b)

Figure 4. (a) Normalized creep force from Vermeulen-Johnson [9] (- - -) and combined with falling part from Huang [11] $(-)$; (b) simulation results for a case without damping.

\subsection{Mode coupling mechanisms}

In addressing curve squeal there is an increase of interest in the direction of mode-coupling phenomena, which have been explained in a simplified form by Hoffmann et al. [12, 13], see also [14]. This type of instability arises from non-conservative displacement-dependent forces and often goes under the name of "flutter". It also occurs in the absence of falling friction. Figure 5(a) shows the typical system adopted to illustrate this mechanism. Here the mass has two degrees of freedom and two springs. As the mass vibrates, variations in the normal load occur, leading to variations in the friction force. This is also equivalent to the system shown in Figure 5(b) in which the modes of the wheel may have both vertical and lateral components and the contact angle $\alpha$ of the wheel with the rail may vary. 
By considering small oscillations around the equilibrium of steady-state sliding, the system in Figure 5 can be mathematically described as

$$
\left[\begin{array}{cc}
m & 0 \\
0 & m
\end{array}\right]\left\{\begin{array}{cc}
k_{11} & k_{12}-\mu k_{H} \\
k_{12} & k_{22}
\end{array}\right]\left\{\begin{array}{l}
x \\
y
\end{array}\right\}=\left\{\begin{array}{l}
0 \\
0
\end{array}\right\}
$$

where the terms $k_{i j}$ in the stiffness matrix depend on the orientation and stiffnesses of the springs [12]:

$$
\begin{aligned}
& k_{11}=k_{1} \cos ^{2} \alpha_{1}+k_{2} \cos ^{2} \alpha_{2} \\
& k_{12}=k_{1} \cos \alpha_{1} \sin \alpha_{1}+k_{2} \cos \alpha_{2} \sin \alpha_{2} \\
& k_{22}=k_{1} \sin ^{2} \alpha_{1}+k_{2} \sin ^{2} \alpha_{2}+k_{H}
\end{aligned}
$$

$k_{H}$ represents the linearized Hertzian contact stiffness [15]; $x$ and $y$ are the vibration displacements in tangential and normal directions. The effect of damping in this system has been studied in [13] and [14] and will be briefly discussed below. The most important feature of equation (2.6) is that the stiffness matrix is non-symmetric. It can be shown [12] that if the upper diagonal term of the stiffness matrix $k_{12}-\mu k_{H} \leq 0$, due to the value of friction coefficient $\mu$, the system can become unstable.

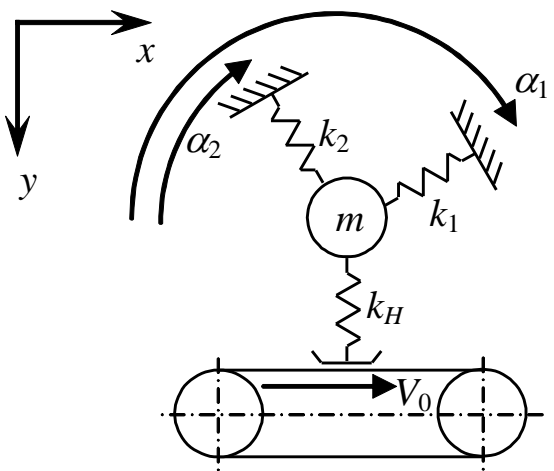

(a)

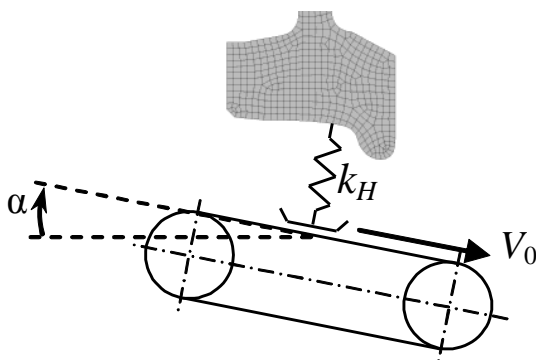

(b)

Figure 5. Two-degree-of-freedom system on moving belt.

To illustrate the mode-coupling mechanism in curve squeal it is convenient to use a modal approach to describe the dynamic properties of the wheel and rail; often modal properties of the wheels are known from finite element (FE) modelling or from modal tests. At least two modes are necessary to initiate this mechanism. Following this idea, as an example equation (2.6) has been adopted to represent the two wheel modes summarised in Table 2. These are arbitrarily chosen but represent possible modes encountered in railway wheels. An extensive parameter study is beyond the scope of this review paper but some examples are shown to illustrate some typical features.

Table 2. Parameters of a two-modes model of the wheel

\begin{tabular}{|c|c|c|}
\hline & Lowest mode & Highest mode \\
\hline Natural frequency (Hz) & 1983 & 1993 \\
\hline Modal mass (kg) & 0.5 & 0.5 \\
\hline $\begin{array}{c}\text { Mode shape at nominal contact point } \\
\text { Normal direction (m) }\end{array}$ & $5.5 \times 10^{-2}$ & $2.7 \times 10^{-2}$ \\
\hline $\begin{array}{c}\text { Mode shape at nominal contact point } \\
\text { Axial direction (m) }\end{array}$ & $2.1 \times 10^{-2}$ & $3.5 \times 10^{-1}$ \\
\hline Damping ratio & $1 \times 10^{-4}$ & $1 \times 10^{-2}$ \\
\hline Rolling velocity (m/s) & \multicolumn{2}{|c|}{2.78} \\
\hline
\end{tabular}

This approach allows investigation of the effect of the lateral position of the contact point (by adjusting the mode shape parameters) or of the inclination of the contact plane (i.e. the contact angle) between wheel and rail $(\alpha$ in Figure 5(b)). Figure 6 shows stability maps obtained for this example by analyzing the real part of the eigenvalues of the system [12]. Results are shown in Figure 6(a) for contact on the wheel tread for different 
values of contact position typical of the leading inner wheel. In this example instability is found for contact positions above $2 \mathrm{~mm}$ towards the flange side. Figure 6(b) shows results for a contact position typical of flange contact for a range of contact angles ( $40 \mathrm{~mm}$ from the nominal position). Here, instability is found for contact angles between $48^{\circ}$ and $65^{\circ}$ for a friction coefficient of at least 0.4 . Although this example is not exhaustive and is given solely for illustrative purposes, it shows that, for these two modes, mode coupling can occur under certain contact conditions and not others.

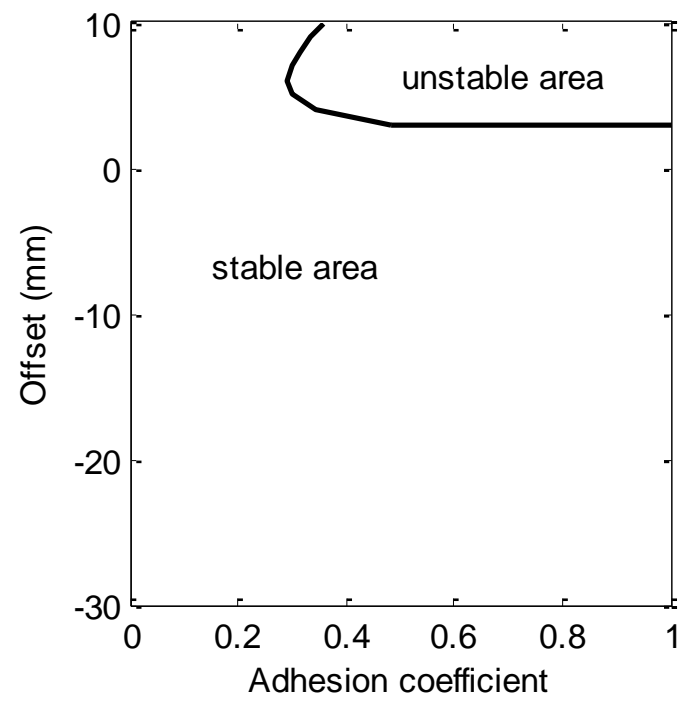

(a)

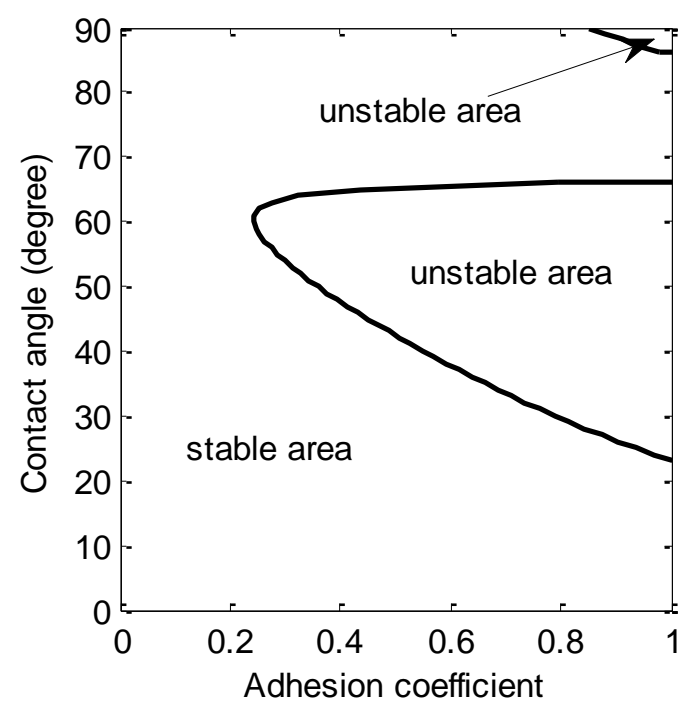

(b)

Figure 6. Stability map for two-mode system with parameters in Table 2: (a) for varying lateral position of the contact and contact angle of $2^{\circ}$; (b) for varying contact angle with a contact position at the wheel flange (40 mm).

Numerical integration of the equations of motion allows the time domain response of the nonlinear system to be obtained. Figure 7(a) shows the corresponding results obtained with the same two wheel modes. Again the simplified creep force model proposed by Vermeulen and Johnson [9] is adopted, see Figure 4(a), but no negative slope is introduced here. A particular combination of friction coefficient and contact angle in the unstable region is chosen according to the stability map in Figure 6(b), with a value of $50^{\circ}$ for the contact angle and 0.6 for the friction coefficient.
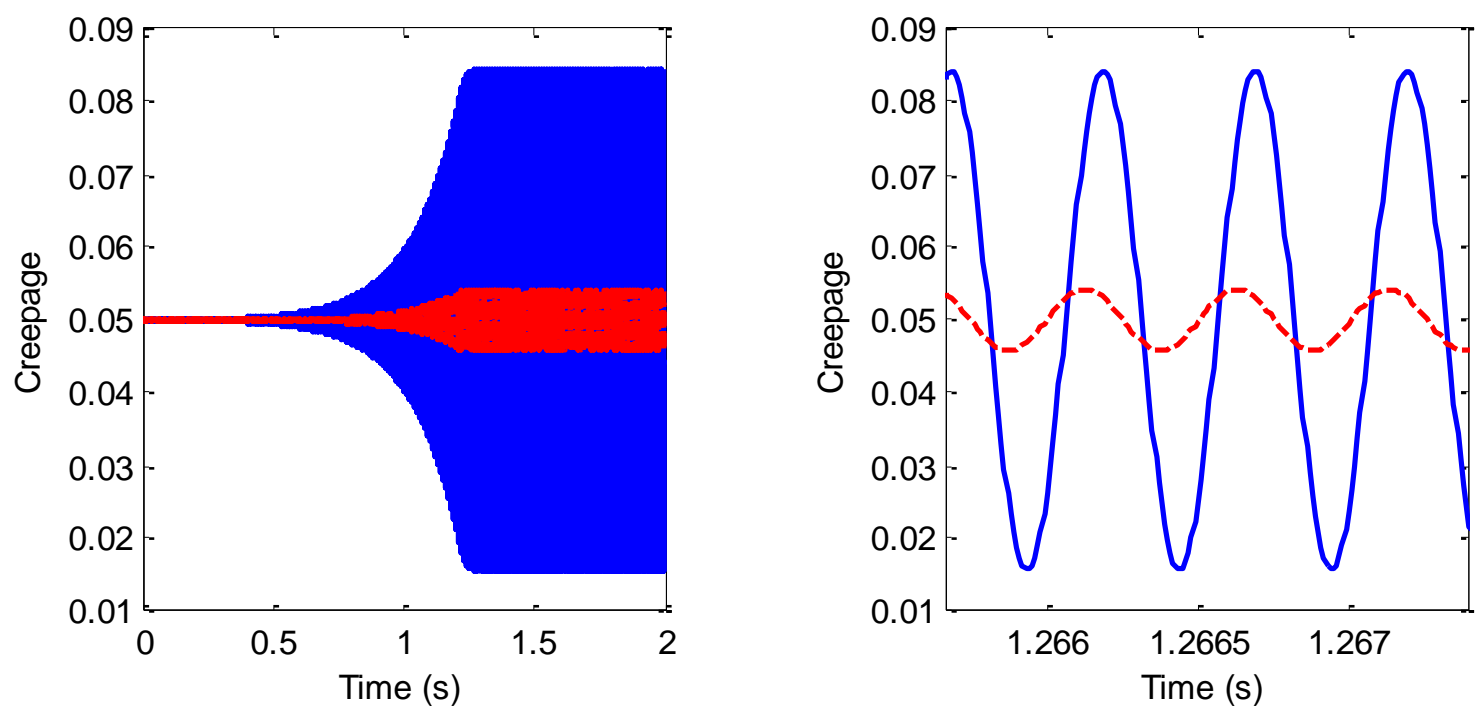
(a)

(b)

Figure 7. Time domain solution for a two-mode wheel. (a) Complete solution; (b) close-up in the limit cycle. Red: normal vibration; blue: tangential vibration (shown as creepage or non-dimensional velocity)

An interesting feature of the response due to mode coupling is that both vertical and lateral vibration can increase to a limit cycle and there is a phase lag between the two directions (see Figure 7(b)). This phase lag is necessary to transfer the energy from one direction to the other one and generate the instability [12].

The effect of damping in the case of mode coupling is not straightforward ([13, 14]); in fact an increase in damping can favour instability in some situations or can improve stability in others. This can be illustrated using the linearized system, again with values from Table 2. Figure 8(a) shows the stability map for varying friction coefficient when the damping ratio of only the second mode is varied, while the damping ratio of the first mode is kept at $10^{-4}$. The system is stable for low values of damping and becomes more unstable when the damping of the second mode is between about $2 \times 10^{-3}$ and $10^{-1}$. Figure $8(\mathrm{~b})$ shows the stability map when the damping ratios of both modes are increased together while keeping their ratio fixed. In this case changing damping has no effect on the stability up to about $10^{-2}$, while the system is quickly stabilised above this value.

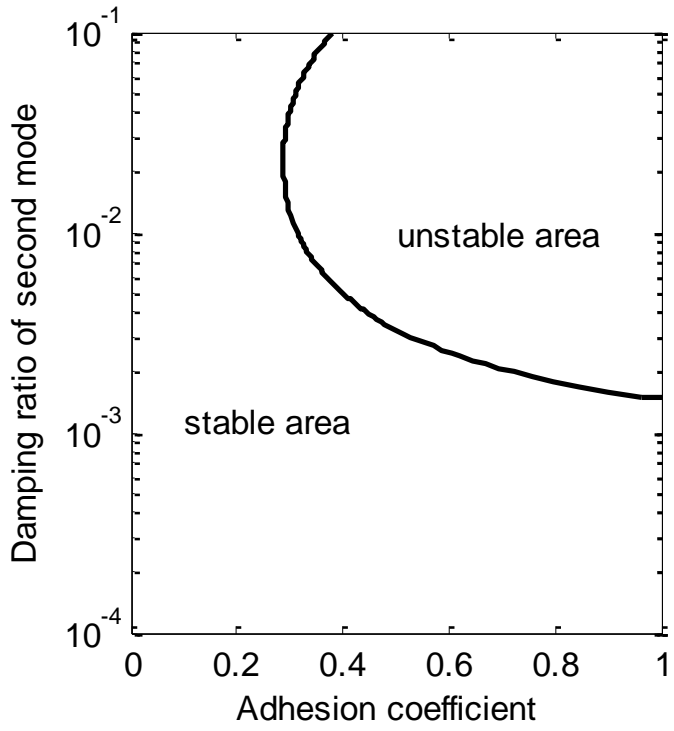

(a)

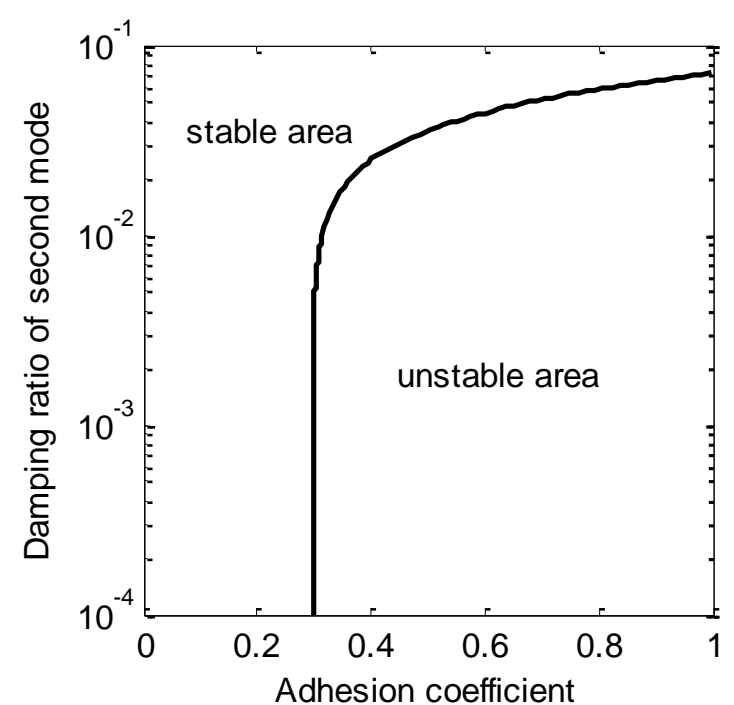

(b)

Figure 8. Stability maps for two-mode system for contact angle $3^{\circ}$ and lateral contact position of $8 \mathrm{~mm}$ showing effect of damping ratio. (a) Damping ratio of second mode only is varied; (b) damping ratio of both modes is varied, keeping the ratio between them fixed.

\subsection{Brake squeal}

A related field which has been widely investigated is automotive brake squeal. Kinkaid et al. [16] gave a thorough review of research in this field, and identify a number of potential mechanisms. These were also reviewed by Ghazaly et al. [17]. Stick-slip due to the negative slope of the friction characteristic (see Section 2.3) was considered for many years to be an essential ingredient of the brake squeal mechanism but more recent work tends to consider it less important. Other mechanisms discussed include 'sprag-slip' due to geometricallyinduced variations in normal force, self-excited vibration under a constant friction coefficient involving mode coupling (as described in section 2.4) and hammering - excitation of disc natural frequencies by impacts between pad and disc. The mode coupling mechanism, in particular between modes of the pad and the disc, is currently the most popular mechanism in brake squeal [17]. Nevertheless it is pointed out that a single mechanism cannot explain all phenomena. Although there are lessons to be learnt from this field for curve squeal, a major difference is that in railway curving the sliding velocities are much smaller than in brake squeal.

Brake squeal modelling often makes use of numerical modelling techniques, representing the disc and pad with finite element models. Ouyang et al. [18] give a review of this approach. 


\section{Modelling}

\subsection{Modelling approaches}

There are two main modelling approaches that can be used for curve squeal. In the first, based in the frequency domain, the system is linearized for small fluctuations in friction force about the steady state values and the stability of the linearized system is studied to determine potential unstable frequencies. In the second, the nonlinear equations are solved directly in the time domain.

In curve squeal studies the two most widely used frequency domain methods used to study the stability of the linearized system are complex eigenvalue analysis and the Nyquist criterion. According to the first method the eigenvalues of the system are first calculated and instability is identified when the real part of at least one eigenvalue becomes positive. The growth rate can be identified from the real part of the eigenvalue. In the second case the system is described by a feedback loop with positive feedback and the Nyquist criterion [19] is applied to the open loop transfer function. The open loop transfer function is plotted on the complex plane and if it encloses the point $(+1,0)$ the system is unstable. In addition, by plotting the magnitude of the open loop transfer function against frequency, the frequencies associated with these unstable points can be identified as likely squeal frequencies. The two methods essentially give similar information: the growth rate is proportional to the ratio of the loop gain to the modal mass of the corresponding mode [20]. Both can give multiple unstable frequencies; the one which will dominate the squeal response depends on the initial conditions as well as the respective growth rates and cannot be determined using these frequency domain methods.

Time domain methods allow the evolution of the response to be determined and the limit cycle amplitude to be obtained taking full account of the system nonlinearities. The calculation effort is much greater, especially for a detailed model of the wheel and track, and this method is therefore more difficult to use in parametric investigations. Nevertheless, with the improvement in computational speed these methods are being used more widely.

\subsection{Wheel dynamic behaviour}

The wheel dynamic behaviour is an important component of curve squeal. In particular, squeal is usually associated with lightly damped modes of vibration of the wheel. Each mode has a harmonic variation in amplitude around the circumferential direction, which can be categorized according to the number of nodal diameters, $n$ [7]. Example modeshapes are shown in Figure 9 for a wheel with diameter $0.84 \mathrm{~m}$. These modes are for $n=2$, but for other values of $n$ the cross-section of the modeshape is similar. Axial modes can be identified according to the number of nodal circles $m$ and will be identified as mode $(n, m)$. Additionally radial $(n, \mathrm{R})$ and circumferential $(n, \mathrm{C})$ modes occur [7].

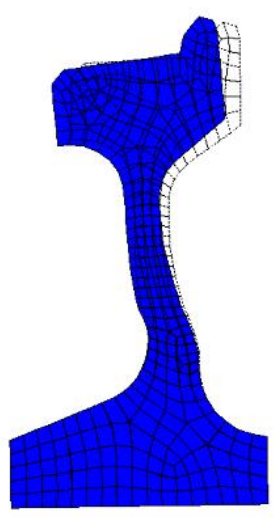

(a)

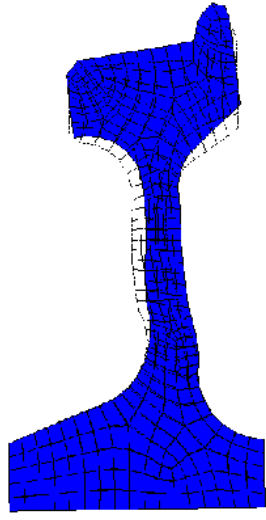

(b)

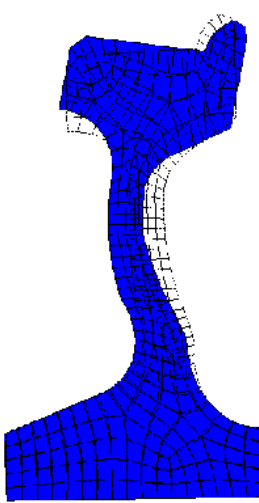

(c)

Figure 9. Examples of mode shapes of Class $15 x$ wheel with $n=2$. (a) 0-nodal-circle axial mode (2,0), 463.0 Hz; (b) radial mode (2,R), $2220 \mathrm{~Hz}$; (c) 1-nodal-circle mode (2,1), $2901 \mathrm{~Hz}$. 


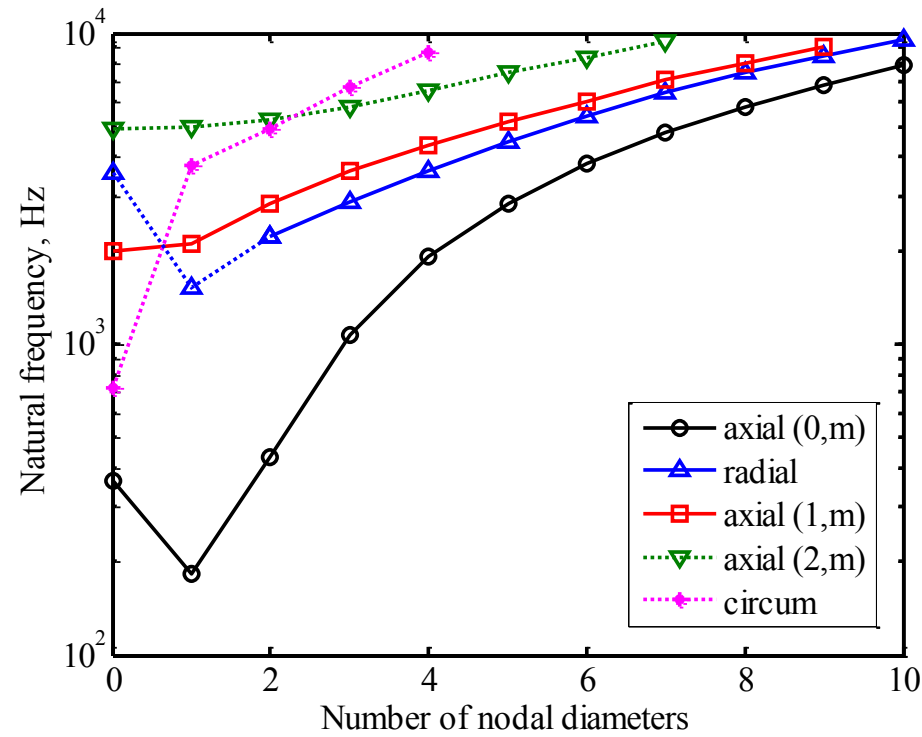

Figure 10. Natural frequencies of Class $15 \mathrm{x}$ wheel, diameter $0.84 \mathrm{~m}$. - measured; ….. calculated.

The natural frequencies of the various mode types of this wheel are plotted in Figure 10 against the number of nodal diameters, $n$. Measured values are plotted using a solid line and, where these could not be identified, corresponding results from finite element calculations are supplied using a dotted line. Generally curve squeal occurs most often in one of the 0 -nodal-circle axial modes which have a large axial component at the wheel/rail contact point and small radial component but, as will be seen, in some situations other mode types are excited. For a monobloc steel wheel, the damping ratio of these axial modes is of the order of $10^{-4}$ for $n \geq 2$. For $n=1$ the modes are strongly coupled with the axle bending and are therefore much more strongly damped due to the bearings. Similarly for $n=0$ the modes are coupled with axle extension or torsion.

\subsection{Models based on falling friction}

Rudd [3] developed an early model of curve squeal, based on excitation by lateral creepage at the wheel/rail contact with instability induced by falling friction in the saturated region, a mechanism first suggested by von Stappenbeck [21]. Rudd's approach was based on the concept of negative damping introduced by the falling friction characteristic; the wheel was represented by a single mode. Rudd's model was also adopted by van Ruiten [22] in an investigation of the squeal noise of trams.

Nakai et al. [23, 24, 25] developed a model in which a stationary steel disc (representing the wheel) is rubbed by a moving rod (representing the rail). This theoretical study shows that squeal noise frequency usually relates to one wheel axial mode with a small damping value. Contact load and contact position were found to have an effect on the occurrence of squeal noise.

Schneider et al. [26] modelled the wheel analytically as a disc and its sound radiation using a Rayleigh integral. They used Kraft's friction model [27] (see Section 4.1.1) and solved the non-linear equations of motion in the time domain. Only the axial 0-nodal-circle modes were included in the calculation; the response was found to contain multiple modes. Fingberg [28] extended the model of Schneider et al. [26] to use a finite element model of the wheel, a dynamic model of the track and a boundary element model for the sound radiation. This was again solved in the time domain. The dominant frequency was found to vary with the rolling velocity. This work has been extended further by Périard [29] who also included the vehicle curving behaviour in the same timestepping calculation procedure as the squeal model.

Heckl and Abrahams [30] presented a simple time-domain model based on the impulse response of a disc, representing the wheel. The lateral friction force was considered as a piecewise linear function with a falling region at large relative velocities and a rising region at small creepages. They showed that the non-linear friction force leads to a limit cycle response, and this limit cycle frequency is determined by one unstable mode of the wheel. Axial modes $(2,0)$ and $(3,0)$ were both unstable but the limit cycle consists of one of these modes, depending on the conditions. Heckl $[31,32]$ also presented a frequency-domain model of the same disc which allowed the growth rate and frequency of the squeal to be determined and its dependence on the damping loss 
factor of the disc to be determined. Measurements were presented of the squeal of this simple disc running on a rotating turntable.

Liu and Meehan $[33,34]$ recently developed a simple single-degree-of-freedom model for curve squeal which neglects vertical dynamics (so no mode coupling is possible) and relies on the negative slope of the friction curve as the source of instability. This is used to explain the increase in sound level with rolling speed and with angle of attack found in a test rig. In their tests, peaks were found corresponding to the axial modes with $n=3$, 4,5 and 6 .

\subsection{Inclusion of vertical dynamics}

De Beer et al. [20, 35, 36] developed a model for squeal noise in the frequency domain, which combines models of wheel dynamics, rail dynamics and contact dynamics in the vertical and lateral directions. For wheel and rail dynamics, mobilities obtained from the TWINS software [37] were used. For the contact dynamics in the vertical direction, a contact spring mobility was adopted, while for the lateral contact dynamics the creepage at low sliding velocities was calculated using the model of Shen et al. [10] and a falling region was introduced using the model of Kraft [27]. The Nyquist criterion was used to assess the stability of the system in the frequency domain. Unstable frequencies were found corresponding to 0 -nodal-circle axial modes with between 2 and 6 nodal diameters. This model appears to be the first in which the variation of the normal contact force was included in a curve squeal model. Although this will potentially introduce mode-coupling phenomena, this possibility was not considered explicitly in this paper and from measurements the presence of squeal was associated with a falling friction curve. The model showed the importance of the lateral position of the contact point on the wheel.

Monk-Steel and Thompson [38] extended de Beer's model to include varying longitudinal and spin creepage as well as lateral creepage and normal load variations. Again only the falling friction aspect was considered. The model was presented in the form of a flow diagram as shown in Figure 11. The upper part represents the excitation due to falling friction, where $[\mathrm{G}]$ contains the mobilities of the wheel and rail system and $\left[\mathrm{H}_{1}\right]$ contains terms from the contact mechanics including the slope of the adhesion coefficient. The term $\left[\mathrm{H}_{2}\right]$ represents the influence of the normal load variations on the transverse forces. The open loop transfer function is given by $\mathrm{H}_{1} \mathrm{G}+\mathrm{H}_{2}$ [11]. In the case where longitudinal and spin creepage are included this feedback loop involves matrices and the generalised Nyquist criterion is used based on the eigenvalues of the open loop transfer function matrix [39]. For a contact point on the wheel tread, squeal was predicted to occur in the 0nodal-circle axial modes with various numbers of nodal diameters.

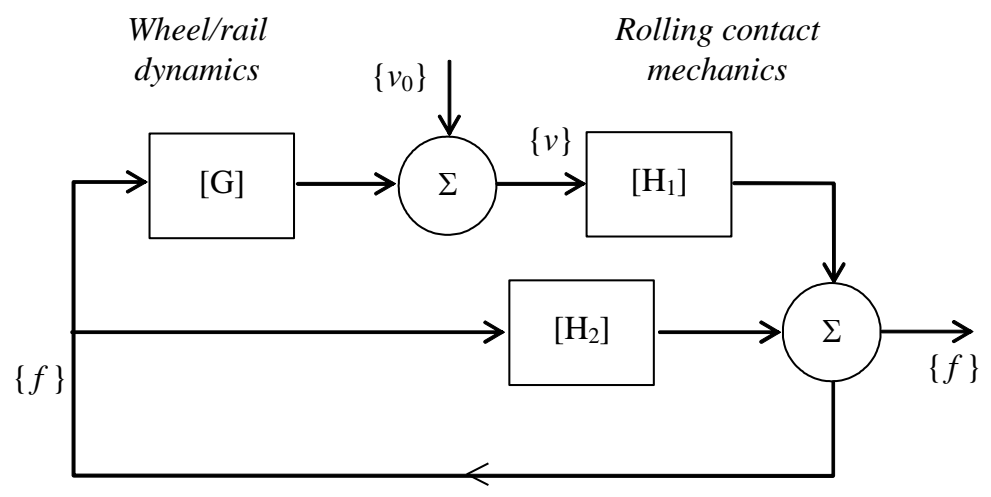

Figure 11. Feedback loop for squeal model [38]

Huang $[11,40]$ also used this approach to extend de Beer's model to include all possible degrees of freedom in the wheel/rail contact and compared results with measurements obtained on a test rig [41]. A heuristic formula for falling friction at large creepages was introduced and combined with the FASTSIM model for rolling contact [8]. Both frequency-domain and time-domain approaches were considered and compared. A parametric study was carried out, which included changing the steady-state creepages, contact position and contact angle. An extension of this model to include the effect of a second contact point was developed following this approach by Squicciarini et al. [42]. They also considered a statistical approach in which the model was run for a large number of cases in which various parameters were selected from a statistical distribution. 
Xie et al. [43] introduced into SIMPACK a modified version of FASTSIM including falling friction as developed by Giménez et al. [44] so that the curving analysis would be consistent with the squeal model.

Chiello et al. [45] developed a squeal model that considered normal contact dynamics. The wheel dynamics was derived from a modal basis. The friction force used included a falling part, linearly decreasing with speed after saturation, which can induce instability. It was pointed out that the asymmetry of the stiffness matrix, leading to mode coupling, can be another possible source of instability but this was believed not to be important by the authors in this particular case and was found to occur only with large lateral offset of the contact point. The modal growth rate was obtained as a measure of stability, which showed that the model could only be destabilised by negative damping. Squeal was predominantly found in the $(3,0)$ axial mode at around $1.1 \mathrm{kHz}$. However, it was found that the dominant mode can be different if different initial conditions are considered, and if harmonically-related modes are present they can coexist in the limit cycle. Collette [46] investigated the influence of vertical dynamics and showed that, even with a constant friction coefficient, this could lead to unstable vibration.

Brunel et al. [47] performed a transient analysis of a wheel using an axi-harmonic finite element model. Two friction laws were considered based on measurements from Kooijman et al. [35], one with a falling characteristic and one with an increasing friction force. It was found that even the positive friction law could lead to a limit cycle solution, which the authors identified with the coupling of the normal and lateral dynamics of the wheel (which they misleadingly refer to as sprag-slip). Nevertheless, it was found that the falling friction characteristic led to much higher levels of squeal. Squeal was found to occur in axial modes with $n=3,4$ and 5 between 1 and $3 \mathrm{kHz}$.

\subsection{Mode coupling}

More recently a number of authors have focussed on the mode coupling mechanism. Glocker et al. [48] stated that the model should be insensitive to the slope of the friction characteristic, and proposed instead an approach based on a constant friction coefficient. They developed an FE model of the wheel and assumed a rigid rail. The mass and stiffness matrices were extracted from the FE model and combined with the contact forces. Friction was included at the contact point. A qualitative comparison was also made with measurements, showing that the squeal frequency of $4.1 \mathrm{kHz}$ was also found in the simulations. They found that three closely-spaced modes were necessary for squeal to occur; of these the mode at $4.1 \mathrm{kHz}$ is the 0 -nodal-circle axial mode with $n=6$, while the other two were a radial mode with $n=4$ and a 2-nodal-circle axial mode with $n=2$.

Pieringer [49] also demonstrated that a model with a constant friction coefficient can show squeal at relevant frequencies. The model was based on pre-calculated impulse response functions of the wheel and rail [50], accounting for the lateral and vertical directions. The model includes an implementation of Kalker's fuller CONTACT method [8]. The value of lateral creepage, the friction coefficient and the lateral contact position on the wheel tread have a strong influence on the occurrence and amplitude of the stick/slip oscillations. Depending on the conditions, squeal occurred at the axial modes $(2,0),(3,0)$ and $(7,0)$, the latter mode at $5.2 \mathrm{kHz}$ being close to the circumferential mode with $n=2$. This work has been extended in [51, 52, 53, 54].

Chen et al. [55] used commercial software to perform Finite Element complex eigenvalue analysis of a wheel in contact with a rail. The rail was only $5 \mathrm{~m}$ long and included springs at the locations of the railpads; it may be remarked that such a rail model will not adequately represent the behaviour of an infinite track. A Coulomb friction model was adopted with a constant friction coefficient, assuming that the lateral creep force has reached saturation. Several wheel modes appeared to be unstable as a result of mode coupling. In one example it was shown that the friction required for instability increases from 0.1 to 0.4 when the railpad stiffness is increased by 50\%. Complex eigenvalue analysis has also been used by Fourie et al. [56] and Wang et al. [57].

\subsection{Other questions}

\subsubsection{Should the rail be included?}

Ding et al. [58] used the curve squeal model from Huang [11] in both the frequency domain and time domain to consider the effect of including or neglecting the rail dynamics. Additionally, the effect of including or neglecting the falling friction characteristic was also considered. Huang's time-domain model was updated to include the rail dynamics in terms of an equivalent state space representation in various directions. Thus, although the track dynamic behaviour is not modal, it can be represented by equivalent modes. The results showed that, although more wheel modes are potentially unstable in the presence of falling friction, this is not the only reason for squeal in Huang's model, mode coupling also being present for some modes. Moreover, rail dynamics can play an important role, especially under constant friction conditions, modifying the unstable 
frequency from $2 \mathrm{kHz}$ without the rail to $1.1 \mathrm{kHz}$ when it is included. In the presence of the rail, the mode coupling can occur between a lightly damped wheel mode and a highly damped equivalent rail mode as well as between pairs of wheel modes. For example, Pieringer et al. [54] have shown unstable coupled wheel-rail eigenmodes that include a significant contribution from the rail.

\subsubsection{Is the effect of wheel rotation important?}

In [51] Pieringer et al. extended the model of [49] to include the effects of wheelset rotation. Three models were compared: stationary wheel, stationary wheel with rotating force and full model of wheel rotation including gyroscopic effects and centrifugal stiffening. At the speed considered, $50 \mathrm{~km} / \mathrm{h}$, no difference was found between the rotating force and the rotating wheel models. Moreover, the stationary wheel model was found to be sufficient to capture the tendency to squeal, although the rotation of the wheel delays the build-up of the stickslip oscillation.

\subsubsection{What is the effect of flange contact?}

Remington [4] reported results from Bleedorn and Johnstone [59] taken on a test rig that showed that flange contact led to noise reductions of over $10 \mathrm{~dB}$. Moreover, it was reported that flange contact alone did not produce squeal. Koch et al. [60] observed on a 1/4 scale rig that for a high angle of attack squeal stopped when flange contact occurred.

Monk-Steel and Thompson [38] presented prediction results for flange contact on the outer wheel as well as for lateral creepage on the inner wheel. These results indicated that flange contact could lead to squeal in radial modes of the wheel rather than axial modes, suggesting that it would have higher frequency content. Squicciarini et al. [42] showed through measurements and modelling that squeal can occur with flange contact and with two-point contact, in this case for a tram system with resilient wheels.

\subsubsection{Contact model}

The model used for the wheel/rail contact dynamics is important in the representation of squeal. Although the steady-state creepage and contact stiffness can be obtained using simplified contact models, more detailed models including transient effects may be needed for a correct representation of the squeal mechanisms. Further study is needed to clarify the differences caused by using different contact models.

\subsubsection{Consideration of the vehicle curving in the model}

Most squeal models assume a constant value of steady creepage as an input. The value of creepage, the contact position on the wheel running surface and the normal load can be obtained from standard vehicle dynamics calculations using commercial or dedicated software. Glocker et al. [48], for example, used commercial software whereas Huang [11] used his own software for steady-state curving in a pre-processing step. Périard [29] used his own model in the same calculation steps as the curve squeal calculation, which leads to unnecessarily small time steps.

\section{Measurements}

\subsection{Laboratory measurements for friction coefficients and squeal noise}

This section provides an historical review on laboratory measurements aimed at measuring rolling friction or adhesion coefficients in both lateral and longitudinal directions and at characterizing curve squeal. Particular attention is given to the presence (or absence) of falling friction as this is becoming a controversial feature in modelling curve squeal.

\subsubsection{Longitudinal creep}

There are many reported results of longitudinal creep force - creepage relations, particularly from the area of locomotive traction; the results summarised here represent a selection but it is by no means exhaustive.

Kraft [27] gave an extensive theoretical investigation of the adhesion between wheel and rail. He reported previous results of field tests by Metzkow and Curtius \& Kniffler; as sliding begins, friction falls rapidly at first and then more slowly. In the case of wet rails the adhesion is reduced further. As used by Schneider et al. [26], Fingberg [28] and de Beer et al. [36], Kraft's formula for the friction coefficient can be written as

$$
\mu=\mu_{0}\left[1-\frac{1}{2} \exp \left(-a /\left|V_{0}\right|\right)-\frac{1}{2} \exp \left(-50 a /\left|V_{0}\right|\right)\right]
$$


with $\mu_{0}$ the static friction coefficient, and $a$ chosen as $0.138 \mathrm{~m} / \mathrm{s} ; V_{0}$ is the sliding velocity.

Logston and Itami [61] present falling friction curves from locomotive traction tests carried out by General Motors. Falling friction was found for dry contact above a creepage of $10 \%$. When a third body is introduced between the surfaces (dry sand, wet sand or oil) the curve starts to fall above 3-5\% creepage.

Ertz [62] reported previous field-test measurements by Lang and Roth [63] where falling friction was observed above about $2 \%$ creepage. In this paper Ertz also focuses on the importance of temperature as well as microroughness in explaining the slope found in the range of full sliding. Polach [64] studied adhesion limits and reported five sets of measurements from locomotives under traction which showed falling friction above a creepage of $0.3 \%$. These measurements included those of Lang and Roth [63] reported by Ertz [62] and of Logston and Itami [61]. The negative slope was steeper at higher speeds. He also developed a model to represent the traction behaviour.

Zhang et al. [65] performed extensive measurements of adhesion coefficient on full scale roller rig. Only the longitudinal direction was considered and various contact condition were investigated. The adhesion coefficient was measured to decrease above $2-3 \%$ creepage and the slope was steeper with higher rolling speeds.

Conversely, Harrison et al. [66] did not detect any presence of falling friction while measuring on a real track with a measurement vehicle and with a hand-pushed tribometer.

Gallardo-Hernandez and Lewis [67] performed roller rig measurements to quantify longitudinal friction with different contaminating materials (particularly leaves). In the case of dry friction negative slope is found above $1-2 \%$ creepage. A possible explanation for the existence of the falling region was given as an increase in temperature due to sliding which can form oxides. Similarly Fletcher and Lewis [68] and Fletcher [69] showed that, for longitudinal friction measurements, the presence of lubricating material removes the negative slope found in dry condition and makes it positive for a wide range of creepage.

Matsumoto et al. [70] presented test rig results for both longitudinal and lateral creepage. They found falling friction for dry contact but in the presence of friction modifiers the force became a rising function of creep velocity.

Results for longitudinal creepage are summarized in the upper part of Table 3. Eight datasets from full scale tests and results from two test rigs all confirm the existence of falling friction; only Harrison et al. [66] reported a constant slope and this was obtained with a hand-push tribometer.

\subsubsection{Lateral creep}

Harrison et al. [66] also presented results from TriboRailer equipment which measured lateral creepage. Some evidence of falling friction was observed, unlike the hand-pushed tribometer based on longitudinal creepage.

Apart from this, the only measurement results available for lateral creepage are from small scale test rigs. Again the results are summarised in Table 3. Although not supported by measurements Rudd's model [3] introduced friction characteristics which fall with increasing sliding velocity above saturation. However Remington [4] compared some results measured on a twin roller rig with Rudd's assumed curve showing broad agreement despite wide variation being found in the results; nevertheless they indicate falling friction above a lateral creepage of $0.9 \%$.

De Beer et al. $[20,36,71]$ used a 1:3 scale model of a wheel on a roller to measure friction coefficient and assess the presence of squeal. A clear relation between measured falling friction and the presence of squeal was observed with this rig: a negative slope was found for angles of attack above $0.3^{\circ}$ (creepage of $0.5 \%$ ) and squeal was detected above $0.4^{\circ}$ (creepage of $0.7 \%$ ), clearly in a region where friction was decreasing with sliding velocity. The average creep forces measured in the presence of squeal were lower than without.

Monk-Steel at al. [72] measured curve squeal noise and friction coefficients on the same 1:3 scale roller rig. The main outcomes are similar to those reported in [36] as curve squeal was detected in a region of falling friction. They also modified the rig to introduce additional longitudinal creepage. For a longitudinal creepage of $2 \%$ the level of lateral creep force was reduced and the shape of the lateral friction curve was modified so that the falling regime developed only at higher values of yaw angle (in this case above $1^{\circ}$ or a creepage of $1.7 \%$ ). Monk-Steel et al. [72] also compared various falling friction characteristics (see also [7]) and showed that, compared with Kraft, the slope of Rudd's model was too severe whereas that of Périard's model was too shallow.

Hsu et al. [41] performed curve squeal and friction coefficient measurements on another 1:3 scale twin disc rig. The forces were measured using strain gauges on the web of the rail roller. The adhesion coefficient did not 
have a clear trend, with regions that could be interpreted as falling and other regions where it was not. Squeal occurred for yaw angles above $1.1^{\circ}$ (creepage of $1.9 \%$ ); above $0.4^{\circ}$ (creepage of $0.7 \%$ ) when damping was added to the rail disc. Huang [11] utilized the same rig and obtained new data from it. In this case a clear falling friction characteristic was found for dry contact. With water added to the contact zone, the friction coefficient was found to be higher than for dry contact and it had a falling region for positive creepage, while it was constant for negative creepage. Huang [11] modified Kraft's [27] formula:

$$
\mu=\mu_{0}\left[1-\lambda \exp \left(-\kappa /\left|\gamma_{0}\right|\right)\right]
$$

in which the constants $\lambda$ and $\kappa$ can be chosen to tune the maximum reduction of friction at large sliding velocity and the rate of decrease respectively. The second exponential term in equation (2.8) was found to be unnecessary for the region of small relative velocities relevant for squeal.

Another rig was adopted by Koch et al. [60] to analyze the effect of rolling speed, lateral position of the contact point, angle of attack and vertical load. This used a 1:4 scale model of a wheelset on a very large roller on which the track was mounted. Squeal was detected for angles of attack above $0.45^{\circ}$ (creepage of $0.8 \%$ ), the sound level increased with speed, vertical load had a negligible effect and lateral position was un-important until flanging; with flange contact, no squeal was observed. Importantly, they did not measure any negative slope. They assumed this was due to measuring the average friction instead of the transient one. For dry friction the slope was positive until an angle of attack of around $1.1^{\circ}$ (creepage of $1.9 \%$ ) above which it was constant. Also with water the friction was lower and constant with increasing creepage. Later Collette [46] repeated measurements on the same rig and again measured squeal in the absence of a negative slope. The author pointed out that the vertical dynamics could play an important role to explain squeal even in the absence of negative slope. Although this is addressed in the paper by introducing a fluctuating vertical force on a single-degree-of-freedom mass-onmoving belt system, the phenomenon would be similar to mode-coupling as described Section 2.4.

Measurements and theoretical modelling for curve squeal in a controlled environment were presented by Liu and Meehan [33, 34, 73, 74, 75]. Measurements were made on a twin disc test rig, with a wheel of radius 0.213 $\mathrm{m}$ and a roller of radius $0.085 \mathrm{~m}$; in most cases these showed a clear trend of squeal occurring with falling friction. Angle of attack and rolling speed increase the noise levels and higher humidity makes squeal more likely. Additionally, by adopting friction modifiers, the negative slope from the friction curve was removed and the friction level decreased. However in some cases this did not result in completely removing squeal. Two possible explanations were given. First, as the friction curve measured is an average over a number of vibration cycles, the authors' hypothesis is that it could be still negative if measured instantaneously. Additionally mode coupling was mentioned as a possible mechanism of squeal with constant friction slope.

Jie et al. [76] performed measurements on roller rig with a whole wheelset; the two rollers can be driven independently. Squeal was associated with negative slope in the friction curve above $0.7^{\circ}$ (creepage of $1.2 \%$ ). Squeal was also observed in the range just before the falling regime. The measured squeal noise spectrum contained several peaks, some of which (but not all) matched resonance frequencies of the wheel observed in the measured driving point mobility. The corresponding wheel modes were not identified.

From this summary it is clear that most of the measurements have found a falling friction coefficient with increasing sliding. It has been pointed out that the friction coefficient measured in these rigs comes from the ratio of average forces over a number of cycles and it is not the instantaneous one, which might take a different shape. What happens at small amplitudes / high frequencies may thus be different from the quasi-static behaviour that can be measured. Koch et al. [60] used this argument to suggest that the instantaneous friction curve may fall even though the curve from the average forces does not. The methods of measuring the normal and tangential forces in the various test rigs also differ, for example using strain gauges on the roller [41] or on the mounting frame [36].

From the papers reviewed, only two authors (Koch et al. [60] and Collette [46]) have reported squeal in the absence of measured negative slope for dry conditions. However the data were collected from the same test rig, presumably with the same approach. Liu and Meehan [75] also found squeal with friction modifiers where a positive slope was obtained. By contrast, results from seven test rigs produced falling friction. Table 3 summarises this by grouping the papers listed above according the quantities measured and highlighting whether falling friction was detected or not. 
Table 3. Summary of rolling friction measurements

\begin{tabular}{|c|c|c|c|}
\hline & & With falling friction & No falling friction \\
\hline $\begin{array}{l}\text { Longitudinal } \\
\text { creep }\end{array}$ & Full scale & $\begin{array}{l}\text { Kraft [27] (Metzkow/Curtius \& Kniffler) } \\
\text { Logston and Itami [61] } \\
\text { Ertz [62] (Lang and Roth [63]) } \\
\text { Polach [64] (five datasets including Logston and } \\
\text { Itami [61] and Lang \& Roth [63]) } \\
\text { Zhang et al. [65] }\end{array}$ & Harrison et al. [66]* \\
\hline $\begin{array}{l}\text { Longitudinal } \\
\text { creep }\end{array}$ & $\begin{array}{l}\text { Reduced } \\
\text { scale }\end{array}$ & $\begin{array}{l}\text { Matsumoto et al. [70] } \\
\text { Gallardo-Hernandez and Lewis [67], Fletcher } \\
\text { and Lewis [68], Fletcher [69] }\end{array}$ & \\
\hline $\begin{array}{l}\text { Lateral } \\
\text { creep }\end{array}$ & Full scale & Harrison et al. [66]* & \\
\hline $\begin{array}{l}\text { Lateral } \\
\text { creep }\end{array}$ & $\begin{array}{l}\text { Reduced } \\
\text { scale }\end{array}$ & $\begin{array}{l}\text { Matsumoto et al. [70] } \\
\text { Remington [4] }\end{array}$ & \\
\hline $\begin{array}{l}\text { Lateral } \\
\text { creep with } \\
\text { curve squeal }\end{array}$ & $\begin{array}{l}\text { Reduced } \\
\text { scale }\end{array}$ & $\begin{array}{l}\text { De Beer et al. [36, 20], Monk-Steel et al. [72] } \\
\text { Hsu et al. [41], Huang [11] } \\
\text { Liu \& Meehan [73, 31] } \\
\text { Jie et al. [76] }\end{array}$ & Koch et al. [60], Collette [46] \\
\hline
\end{tabular}

* tribometers

\subsection{Field measurements of curve squeal}

There are many measurements of squeal in different situations; some recent ones will be reviewed briefly here. However, it has to be remembered that it is difficult to draw general conclusions as the phenomena may differ from one situation to another. Eadie et al. [77] identified 'top-of-rail' squeal as occurring in the frequency range $1-5 \mathrm{kHz}$ and flanging noise in the range 5-10 kHz. Bullen and Jiang [78] gave algorithms for detecting squeal. They distinguished between curve squeal, which occurs at the inner wheel, has high levels, is persistent and tonal, and flanging noise which occurs at the outer wheel, is less loud, intermittent and more "broad-band" (see also [1]).

\subsubsection{Suburban trains}

Glocker et al. [48] (see also [79]) reported a series of measurements of suburban trains on a $200 \mathrm{~m}$ radius curve and track with timber sleepers. The actual gauge was slightly wider than nominal at $1450 \mathrm{~mm}$. In 62 out of 83 events squeal could be uniquely attributed to the inside of the curve. Of these, 32 events were attributed to the leading inner wheel; the main squeal frequency was $4.1 \mathrm{kHz}$. Squeal at the outside of the curve was also observed but much less frequently. Additionally some flanging noise was observed from the outside wheel with a much wider range of frequency peaks.

Vincent et al. [80] measured sound with microphones adjacent to the four wheels of a bogie. Tests were conducted on a metro vehicle with monobloc wheels on a curve of radius $75 \mathrm{~m}$ at different speeds between 10 and $40 \mathrm{~km} / \mathrm{h}$. Squeal occurred at frequencies corresponding to 0 -nodal-circle axial modes with 2, 3 and 4 nodal diameters, with natural frequencies $450 \mathrm{~Hz}, 1.1 \mathrm{kHz}$ and $2.0 \mathrm{kHz}$; different modes squealed at different stages of the curve. The leading inner wheel always dominated the squeal.

In an unpublished study by the authors at a new line in London, UK, squeal was found on a curve of radius $180 \mathrm{~m}$ at $800 \mathrm{~Hz}$ (corresponding to a circumferential mode) and at $1.2 \mathrm{kHz}, 2.3 \mathrm{kHz}$ and $4 \mathrm{kHz}$ (axial modes with 3, 4 and 6 nodal diameters). At another curve, the same trains produced strong peaks at $7.25 \mathrm{kHz}$ and $9.4 \mathrm{kHz}$; this noise appeared subjectively to be 'flanging'. The corresponding wheel modes were either radial modes with 8 and 10 nodal diameters or axial modes with 9 and 11 nodal diameters, as in each case both modes types occur close to the peak frequency. 


\subsubsection{Freight trains}

Extensive field trials have been conducted in Australia on both suburban and freight trains, including monitoring the effect of friction modifiers [1, 2, 81, 82, 83]; the angle of attack of each passing wheelset has also been monitored. Two main categories of squeal were identified by Anderson et al. [1, 81]. In the first, named 'friction controlled', a moderate level of squeal was generated by approximately $10 \%$ of passing stock. Squeal could be controlled by top-of-rail friction modifiers and is also affected by environmental conditions, its occurrence therefore appearing random. The second category, 'steering controlled', often leads to severe squeal associated with particular vehicles (less than $2 \%$ ). In such cases squeal was found to be caused by freight vehicles with high angles of attack associated with poor lubrication of the centre bowl (where the bogie pivots relative to the vehicle body) [1]. A third category is called 'systemic' in which the majority of vehicles squeal. It is suggested that the underlying effects involve one or both of the friction controlled and steering controlled types but that they are not isolated to a small proportion of rolling stock or friction conditions.

Jiang et al. [84] reported measurements on a $284 \mathrm{~m}$ radius curve in Sydney, Australia. The majority of squeal events from freight trains were associated with the outer wheel; nevertheless these were identified as squeal rather than flanging noise. Correlation with angle of attack showed a higher probability of squeal and potentially higher noise levels with increasing angle of attack: below $15 \mathrm{mrad}$ less than $0.1 \%$ of wheels squealed and noise levels were below $110 \mathrm{~dB}$; this increased to $10 \%$ of wheels for $25-35$ mrad with noise levels of up to $130 \mathrm{~dB}$. Conversely the occurrence of flanging noise showed no obvious relationship with angle of attack. Jiang et al. [85] gave further experimental evidence which showed that squeal events from the outer wheel could be dramatically reduced by good lubrication of the outer rail gauge face. Squeal frequencies were identified as being predominantly in the region $1-3 \mathrm{kHz}$ although both lower and higher frequency events were also found.

For heavy haul trains on a large radius curve (1000 m radius) squeal was detected by Fourie et al. $[56,86]$ at the trailing inner wheel of some unloaded wagons when the outer wheel was in flange contact. At this wheel the angle of attack was estimated to be very small while longitudinal creepage (estimated from the rolling radius difference) was above $1.2 \%$ and exceeded saturation. Squeal occurred mainly around $4-5 \mathrm{kHz}$ and was identified with a circumferential mode with 2 nodal diameters and radial modes with 6 and 7 nodal diameters. The dependence of frequency on wheel radius was also shown. It was suggested from the proximity of pairs of modes that mode coupling is responsible, although it appears that falling friction associated with longitudinal creepage cannot be ruled out.

\subsubsection{Trams}

Trams are usually fitted with resilient wheels which have higher damping than monobloc wheels, typically greater by at least a factor of 10 . However, trams also negotiate very tight curves, which increases the likelihood of squeal.

Van Ruiten [22] presented squeal noise measurements on three tram systems in the Netherlands for speeds of $15-20 \mathrm{~km} / \mathrm{h}$. All were fitted with resilient wheels of various types; measurements were also reported with a variety of track systems. Squeal was found to occur mainly in the $500 \mathrm{~Hz}, 1250-1600 \mathrm{~Hz}$ and $2500 \mathrm{~Hz}$ one-third octave bands irrespective of the track system and this was associated with the axial modes with 2, 3 and 4 nodal diameters. Mostly the highest levels were measured at the inside of the curve.

Corradi et al. [87] presented a series of measurements on a tram in Milan, Italy with resilient wheels on a very sharp curve with radius $17.5 \mathrm{~m}$ and grooved rails. The vehicle speed was $10 \mathrm{~km} / \mathrm{h}$. Wheel vibration was also measured during running and it was found that both inner and outer wheels exhibited high vibration levels, although the amplitude on the inner wheels was the highest. The noise levels were similar on both sides of the tram. These measurements are interesting in that the peak frequency of squeal, around $1.5 \mathrm{kHz}$, did not correspond to a mode of vibration, the nearest modes being at $1273 \mathrm{~Hz}$ and $1423 \mathrm{~Hz}$, both of which have $n=3$, one being predominantly axial and the other radial. In [42] this frequency shift was associated with two-point contact; however, it may also be evidence of mode coupling. Measured damping ratios were also presented in [87] which are between 0.004 and 0.014 .

Vincent et al. [80] also measured squeal from a tram fitted with resilient wheels on a $60 \mathrm{~m}$ radius curve with grooved rails. It was found that in most cases the highest noise levels were related with the leading inner wheels, but in one case the rear outer wheel was also observed to squeal for a trailer bogie with independent wheels when the speed was higher. All axial modes between $n=3$ and 9 nodal diameters were excited (1.2 to $8.1 \mathrm{kHz})$. Vincent et al. [80] also measured the modal damping of the resilient wheel, finding damping ratios between 0.002 and 0.008 . 
In [88], Merideno et al. found that squeal occurred for the trams in Vitoria, Spain which have resilient wheels; the squeal frequencies correspond to the axial wheel modes with $n=2(780-800 \mathrm{~Hz})$. The curve radius in the tests was $25 \mathrm{~m}$.

\subsubsection{Check rail contact}

The introduction of new trains in the UK in the 1980s led to a severe curve squeal problem with noise levels of 130-145 dB measured close to the wheels [7]. Measurements were carried out with microphones close to each wheel of a bogie on the line between Llandudno and Blaenau Ffestiniog in Wales, on which there are many curves with radius $200 \mathrm{~m}$ fitted with check rails. It was identified that squeal occurred at the leading inner wheel and was associated with radial modes with 2-5 nodal diameters $(2.2-4.5 \mathrm{kHz})$. It was determined that these modes were excited by contact between the back of the wheel flange and the check rail.

\subsubsection{Summary}

The various measurements reviewed here are summarised in Table 4, arranged in order of curve radius. Clearly squeal can occur at a wide range of frequencies; results have been noted between $450 \mathrm{~Hz}$ and $8 \mathrm{kHz}$. Usually the leading inner wheel of a bogie dominates the squeal: the main exception to this was the measurements on freight wagons by Jiang et al. [84] where the majority of squeal events were associated with the outer wheel (it is not stated whether this was the leading or trailing axle). Corradi et al. [87] found squeal on both inner and outer wheels of a tram.

Table 4. Summary of curve squeal measurements

\begin{tabular}{|c|c|c|c|c|c|c|}
\hline Reference & Train type & $\begin{array}{l}\text { Curve } \\
\text { radius }\end{array}$ & $\begin{array}{l}\text { Dominant } \\
\text { frequency } \\
(\mathrm{Hz})\end{array}$ & Wheel modes & Wheel & Notes \\
\hline $\begin{array}{l}\text { Corradi et al. } \\
{[87]}\end{array}$ & tram & $17.5 \mathrm{~m}$ & 1500 & $(3,0)+(3, \mathrm{R})$ & $\begin{array}{l}\text { Inner and } \\
\text { outer }\end{array}$ & Resilient wheels \\
\hline $\begin{array}{l}\text { Merideno et } \\
\text { al. [88] }\end{array}$ & tram & $25 \mathrm{~m}$ & 800 & $(2,0)$ & $\mathrm{n} / \mathrm{a}$ & Resilient wheels \\
\hline $\begin{array}{l}\text { Vincent et al. } \\
{[80]}\end{array}$ & tram & $60 \mathrm{~m}$ & $1200-8100$ & $(3,0)-(9,0)$ & Leading inner & Resilient wheels \\
\hline $\begin{array}{l}\text { Van Ruiten } \\
\text { [22] }\end{array}$ & tram & $\mathrm{n} / \mathrm{a}$ & $\begin{array}{l}500,1250, \\
1600\end{array}$ & $(2,0),(3,0),(4,0)$ & Inner & Resilient wheels \\
\hline $\begin{array}{l}\text { Vincent et al. } \\
{[80]}\end{array}$ & suburban & $75 \mathrm{~m}$ & $\begin{array}{l}450,1100 \\
2000\end{array}$ & $(2,0),(3,0),(4,0)$ & Leading inner & \\
\hline unpublished & suburban & $180 \mathrm{~m}$ & $\begin{array}{l}800,1200 \\
2300,4000\end{array}$ & $\begin{array}{l}(0, C),(3,0), \\
(4,0),(6,0)\end{array}$ & $\mathrm{n} / \mathrm{a}$ & \\
\hline $\begin{array}{l}\text { Glocker et al. } \\
{[48]}\end{array}$ & suburban & $200 \mathrm{~m}$ & 4100 & $\begin{array}{l}(6,0) \text { with } \\
(4, R)+(2,2)\end{array}$ & Leading inner & \\
\hline Thompson [7] & suburban & $200 \mathrm{~m}$ & $\begin{array}{l}2200,2800 \\
3600,4500\end{array}$ & $(2, R)-(5, R)$ & Leading inner & Check rail \\
\hline $\begin{array}{l}\text { Jiang et al. } \\
\text { [84] }\end{array}$ & freight & $284 \mathrm{~m}$ & $1000-3000$ & $\mathrm{n} / \mathrm{a}$ & Outer & $\begin{array}{l}\text { Large AoA } \\
\text { (AoA measured) }\end{array}$ \\
\hline $\begin{array}{l}\text { Fourie et al. } \\
{[56,86]}\end{array}$ & freight & $1000 \mathrm{~m}$ & $4000-5000$ & $\begin{array}{l}(2, C),(6, R), \\
(7, R)\end{array}$ & Trailing inner & $\begin{array}{l}\text { Longitudinal } \\
\text { creep }\end{array}$ \\
\hline
\end{tabular}

The modes excited are nearly always $(n, 0)$ axial modes, consistent with the models described in Section 3 . Some special cases have been identified where this is not the case: (i) Fourie et al. $[86,56]$ where the dominant mode was circumferential, (ii) the case of check rail contact [7] described in Section 4.2 .4 where the radial modes were excited and (iii) Corradi et al. [87] where the squeal frequency did not correspond closely to a modal frequency. The squeal from the trams in [87] may be affected by contact between the flange and the groove rail due to the very sharp radius. 


\section{Mitigation}

A range of mitigation measures is available to tackle curve squeal; these are discussed, for example, in [7, 89, 90, 91, 92]. These include lubrication and friction modifiers, wheel and rail damping treatments, improved curving behaviour and changes to rail transverse profiles. In discussing noise mitigation measures, it should be emphasised that the desirable outcome is the elimination of squeal or reduction in its occurrence. Although many sources quote noise reductions these have limited value as they cannot be applied to other situations.

\subsection{Lubrication and friction modifiers}

There have been many attempts to control squeal using lubrication and friction modifiers. Friction modifiers $[93,94]$ are intended to replace the falling friction characteristic by a flat or even increasing ('positive') friction characteristic [70] while maintaining the level of friction coefficient in a range suitable for adhesion and braking requirements. On the other hand oil-based lubricants often lead to lower friction levels and should therefore be avoided on the rail head. Lubricants, such as oil-based grease, are often applied on the wheel flange or rail gauge face. As well as their possible effect on squeal excitation they modify the curving behaviour of the vehicles and reduce wear. If the dominant excitation mechanism is mode coupling, the introduction of 'positive' friction via a friction modifier may still not suppress the squeal, although the general lowering of friction level will help.

Eadie et al. [77, 93, 94] reported a number of field tests of friction modifiers applied to the top of the rail, which were successful in reducing squeal noise. These were applied by a trackside applicator system. They were also shown to have a beneficial effect on reducing corrugation growth in curves. Suda et al. [95] described an onboard system used to spray friction modifier onto the rail head which was found to reduce the presence of squeal.

Liu and Meehan [75] investigated the friction and squeal performance of friction modifiers on a twin disc test rig. They found that the negative slope of the friction curve was replaced by a positive friction characteristic with a lower level of friction. Nevertheless squeal was not always suppressed. They hypothesised that the instantaneous friction curve could still have a negative slope but it is also possible that mode coupling was influencing the squeal.

Of the two main categories of squeal identified by Anderson et al. [1, 81], it is stated that 'friction controlled' squeal could be controlled by top-of-rail friction modifiers. In the second category, 'steering controlled', top-ofrail friction modifier is often only partially effective. It is stated that gauge face lubrication does not influence squeal but can often influence flanging noise, although this is not always the case [1]. However, Curley et al. [82] summarised the results of 16 lubrication scenarios applied in sequence to a single curve with radius $290 \mathrm{~m}$ where freight traffic regularly squealed. At this location squeal was successfully mitigated by gauge face lubrication on the outer rail whereas top-of-rail friction modifiers on the inner rail were not successful. This suggests that the outer wheel was squealing, as found by Jiang et al. [84].

Water can also be used to mitigate squeal noise; indeed experience shows that squeal often disappears during rain. In the measurements of Corradi et al. [87] on a tram in Milan, by applying water over both rails, the curve squeal disappeared completely. However, although not reported, it was observed that high squeal levels occurred after rain when the track was starting to dry out. Liu and Meehan [74] found, by monitoring squeal noise in a test rig in a controlled environment, that squeal is more likely at higher humidity levels.

A water mist spray system was used in the early 2000 s as a trial on a $300 \mathrm{~m}$ radius curve at Barnt Green, near Birmingham, UK [92]. Monitoring of the site showed that the mist spray system reduced the occurrence of squeal from $14 \%$ to $2.5 \%$ of the time [92]. However, in the winter the system had to be drained. The system was later removed [91] and replaced by a system applying a friction modifier.

\subsection{Wheel damping treatments}

Wheel damping treatments have long been seen as a potential solution for curve squeal yet in practice they are not always successful. To understand this, the models are again helpful. According to the falling friction model, if the damping level can be increased so that it exceeds the negative damping of the friction force (equation (2.5)), the system should be stable. This can lead to dramatic noise reductions from only moderate increases in damping. However, where mode coupling exists the picture is less clear and an increase in damping does not always stabilise the system, see Figure 8. Resilient wheels have a much higher initial damping than solid wheels but squeal can still occur with them in tight curves. 
There are many types of wheel damper that are commercially available, including tuned absorbers, constrained layer treatments and ring dampers [7, 89, 90, 91], see Figure 12(a-c). Also shown in Figure 12(d) is a resilient wheel. It is unfortunate that most published results on the effect of wheel dampers focus on noise reductions, which are situation-dependent, whereas the modal damping values achieved would be more generally useful.

(a)

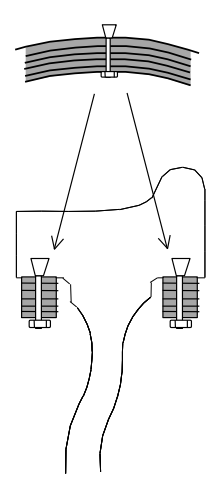

(b)

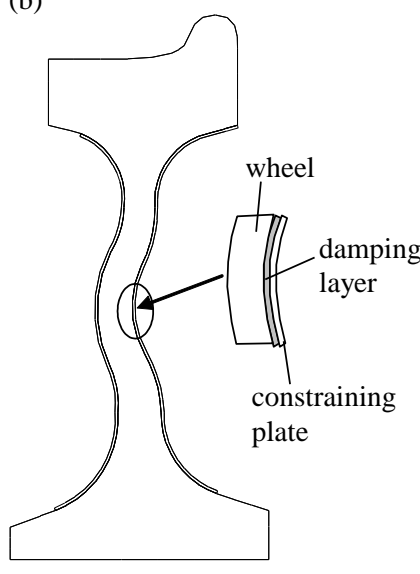

(c)

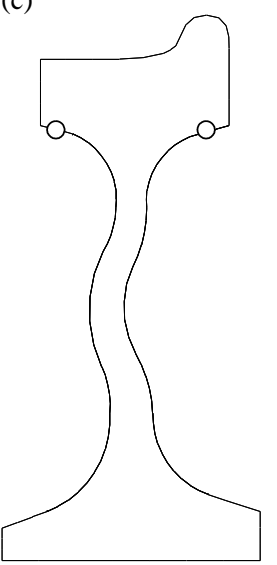

(d)

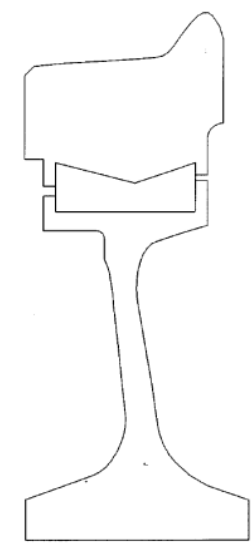

Figure 12. Examples of wheel damping treatments: (a) tuned absorbers; (b) constrained layer damping; (c) ring dampers; (d) resilient wheel.

Bühler and Thallemer [96] reported results of applying tuned absorbers on the wheels. In one case, over a range of curves, squeal was initially found at frequencies $2-8 \mathrm{kHz}$ for curve radii less than $170 \mathrm{~m}$ and this was eliminated by the introduction of the wheel absorbers. However, in another case with a squeal frequency of 700 $\mathrm{Hz}$ no improvement was observed.

Constrained layer damping applied to the wheel web was successful in suppressing the severe squeal problem in the UK caused by flange-back excitation by contact with a check rail [7] (see Section 4.2.4). Recent measurements have shown that the average damping ratio was increased from $6 \times 10^{-5}$ to $7 \times 10^{-4}$. Although this is still quite low, the squeal was completely eliminated (yielding reductions in overall noise level of more than 30 $\mathrm{dB})$. Jones and Thompson [97] described a calculation method for determining the damping of wheels with constrained layer treatments based on a finite element model.

Merideno et al. [88] described the development of a damper system applied to eliminate squeal in trams occurring at 780-800 Hz. Due to the limited space available on the small resilient wheels, the damper was attached on the inside of the wheel tyre and consisted of a cantilevered plate attached to a damping layer. This is described as a tuned constrained layer treatment and in fact resembles typical tuned absorber systems. The damper successfully eliminated squeal.

Ring dampers are potentially attractive as the added mass is minimal. They are considered for example in [46, $98,99]$. These consist of a metal ring that sits in a groove in the inner side of the tyre. It is believed that friction between the ring and the groove leads to increased damping although the mechanism is not fully understood. Their damping effect is smaller than other systems but is often sufficient to suppress squeal; the mechanism is also nonlinear making the effect amplitude-dependent.

Marjani and Younesian [100] presented a theoretical study of the use of piezoelectric patches on the wheel surface as a means of introducing damping. These are shunted through either a resistance shunt circuit or a resonant shunt circuit. Modest increases in modal damping were reported.

Active control of vibration is another potential technique for controlling wheel vibration. Heckl and Huang [101] proposed a simple active control system as a means of preventing squeal. A simple feedback control system was used based on a filtered signal centred on the squealing mode. It was claimed that the energy requirement is much less than conventional active control. The system was applied to a small scale test rig and was shown to suppress squeal noise. To the authors' knowledge such an active control system has not been applied on a railway vehicle. 


\subsection{Rail damping and track dynamics}

It is potentially attractive to consider treatments that can be applied to the track at sites where squeal occurs, rather than having to treat whole fleets of vehicles that pass the site. One such treatment is the use of rail dampers, e.g. [102]. However, there is no direct evidence that rail dampers are effective in reducing squeal [7]. Although the rail vibrates during curve squeal, its amplitude is often (although not always) much smaller than that of the wheel. Rail dampers are usually installed to increase the track decay rate to reduce rolling noise; typical reductions of rolling noise are between 2 and $6 \mathrm{~dB}$ depending on the rail pad stiffness [7]. A higher track decay rate would also reduce the rail component of squeal noise (which may be significant e.g. in flanging noise) but it would not affect the wheel component. On the other hand, if the mechanism is mode coupling, rail dampers may have an influence by increasing the damping of 'modes' of the rail (see Section 4.4.1).

At the site in London, UK, mentioned in Section 4.2.1, rail dampers were fitted to the curve in 2015. Following installation it appears that there was a noticeable reduction in the occurrence of curve squeal. However, as friction modifiers had also been applied at the curve prior to the installation of dampers, it is not certain this improvement was due to the rail damping. Nevertheless, it appears that they played a part. Anecdotally it appears that the rail dampers have been successful in reducing the longer duration squeal events which previously occurred at the site.

As reported by Jiang et al. [103], squeal has been found to occur more severely after replacing timber sleepers by concrete. The reasons for this are unclear, but in the study the track mobilities, decay rates and dynamic gauge were investigated. The point mobility of the track with concrete sleepers showed clearer resonances (which may lead to stronger mode coupling) while the track with timber sleepers had a higher decay rate. The authors claim that this will remove energy from the wheel and therefore mean less squeal propensity but it can be pointed out that undamped wave propagation in an infinite rail also removes energy from the wheel. Finally the track with timber sleepers is more flexible leading to an increase in dynamic gauge spreading during a train passage. This can lead to changes in curving behaviour and also to the location of the contact patch on the wheel (see Section 5.5).

Chen et al. [55], by performing FE complex eigenvalue analysis, found that changing the stiffness of the rail support can suppress or eliminate curve squeal. However their model of a short length of rail is unlikely to represent the behaviour of an infinite track adequately.

\subsection{Improved curving behaviour}

As noted in Section 2.1, the yaw stiffness of the primary suspension is required to provide stability of running at high speed, preventing hunting, but this can have an adverse effect on the curving behaviour. If the wheelsets can be arranged to align radially to the curve this will prevent the large angles of attack and hence squeal will not be generated. This also has benefits in reducing wear and rolling contact fatigue. For example, Axiom's LN25 bogie has a radial arm design suspension which allows greater yaw angles than the industry standard Y25 bogie. A recent study [104] has shown that the LN25 bogie will have a reduced likelihood of curve squeal as a result. In [96] it is reported that on the MOB in Switzerland less squealing was observed with bogies which allow radial steering, however no details were given.

Anderson et al. $[1,81]$ found at some sites that a small number of freight wagons caused large squeal levels. These events were identified with wagons in which the centre-bowl lubrication was ineffective, leading to large angles of attack. Targeted maintenance helped to reduce these severe events. Moreover, it is well known that increasing wheel conicity improves curving behaviour (and reduces critical speed). High conicity profiles reduce the angle of attack although the authors are unaware of any paper that relates conicity with squeal.

Passive steering mechanisms including cross-bracing between the axles of a bogie have been applied on various vehicles to achieve 'radially steered wheelsets' [6]. One example of this is the cross-braced bogie, introduced in the early 1980s [105] and applied particularly on freight wagons. However, in a theoretical study [106] it was found that a well-optimised conventional bogie may offer curving performance close to, or even better than, that of radial bogies.

As well as such passive systems, there has been considerable interest recently in active control of vehicle suspensions. Bruni et al. [107] gave a review of monitoring and control systems applied to railway vehicle dynamics. Of interest here are active primary suspensions in which the yaw of the wheelsets is modified by actuation with the aim of improving curving behaviour while maintaining stability at high speed. Systems based on independently rotating wheels were also reviewed, in which case active control is required also to provide steering and guidance, this being provided passively in the case of the solid wheelset. Various prototype systems 
have been demonstrated [107] and it can be expected that such mechatronic bogies will be introduced in the future.

As an alternative to the control of the primary suspension, active control of yaw in the secondary suspension has also been considered [107]. This applies a yaw torque to the bogie to improve stability; in curved track curving performance can be improved by using the yaw torque to equalise the lateral forces on the two axles. Such systems have been implemented in an operational system [107].

\subsection{Rail profiles, surface treatments and changes to gauge}

Hiensch et al. [108] described a two-material rail intended to be resistant to rolling contact fatigue and to reduce squeal noise. Surface coatings were applied either during rolling of the rails or by laser cladding. However, field tests did not show any reduction in curve squeal [91]. Similarly, in [96] it was reported that two unspecified systems for rail running surface conditioning were evaluated in Switzerland. They did not eliminate squeal but gave small reductions in noise level (2-5 $\mathrm{dB}(\mathrm{A}))$.

De Beer et al. [36] showed that the lateral contact position on the wheel affects the occurrence of squeal; being able to control this could in principle be used as a form of noise control [36]. The wheel they studied on their test rig was symmetrical and only showed squeal for contact positions to one side of the centreline. For a more realistic asymmetric wheel design the dependence on contact position is more complex [7].

One way to move the contact patch location on the wheel is to modify the rail transverse profiles. Asymmetrical profiles from Austria are reported in [109] (see also [90]). However, a pilot study with such profiles in Switzerland only showed positive effects for one type of passenger train [91]. At a site at Wollstonecraft, NSW, Australia with $200 \mathrm{~m}$ radius, application of asymmetric rail profiles proved unsuccessful [1]. In the Netherlands, a special anti-squeal rail profile was tested in Den Haag on a $200 \mathrm{~m}$ radius curve [91]. The profile did not reduce the number of squeal events, but the average sound level per squeal event was reduced by $3 \mathrm{~dB}$. On a second test section with the anti-squeal rail profiles, the inner rail was impregnated with tungsten carbide (a material with a very high hardness). This reduced the number of squeal events from $74 \%$ to $26 \%$. The average sound level of the squeal events was again reduced by $4 \mathrm{~dB}$.

The contact position can also be modified by varying the track gauge, although this also affects the angle of attack. It will depend on the wheel design whether gauge widening or narrowing is preferable. It can also be postulated that the presence of two-point contact may reduce the likelihood of squeal. The presence of high longitudinal creepage can also be effective in eliminating the falling friction characteristic from lateral creep [72] but may itself excite circumferential modes [86].

\section{Concluding remarks}

Curve squeal remains a difficult problem, with the phenomenon appearing random rather than deterministic. Nevertheless, some success has been achieved in recent years using deterministic models to represent squeal behaviour. The main outstanding controversy is the relative importance of the falling friction mechanism compared with mode coupling. It is the authors' opinion that falling friction should not be ruled out as there is strong evidence for the existence of falling friction characteristics. However, the measurements of friction that are available from test rigs are quasi-static. What happens at small amplitudes and high frequencies may be quite different from this quasi-static behaviour that can be measured and indeed may not contain a negative slope at all. Mode coupling may contribute to an explanation for why some wheels squeal more than others; angle of attack is also important.

It should be recognised that squeal is not a single phenomenon and different phenomena may require different modelling approaches and different treatments. Although most cases reported involve 0-nodal-circle axial modes excited at the leading inner wheel, some unusual occurrences have been highlighted where different phenomena are involved. Even for the axial modes at the leading inner wheel, the dominant mode may vary over a wide frequency range, with values of $n$ from 2 to 9 . The reasons for this are not clear.

Curve squeal is almost always associated closely with one or more wheel modes. Nevertheless the importance of the rail has also been highlighted. The review has not covered rail vibration measurements or the contribution of the rail radiation to noise; its importance will vary depending on the excitation mechanism. Where the squeal frequency is very close to the natural frequency of the wheel, the rail vibration will exhibit the same frequency components but its response will be small compared with the wheel. However, where the squeal frequency is not exactly at a wheel mode the relevance of the rail response will increase. 
Much of the data from field measurements reviewed is extensive, but it has to be commented that no dataset is complete. In particular, the friction characteristic is usually missing; no field test results are available for lateral friction characteristics. Modal identification of the wheels is only possible for test trains, not for service trains. The frequency response of the rails may also be important but is not often measured in the context of squeal investigations. The curving behaviour of the vehicles, particularly the angle of attack, is also very important but has only been reported in very few cases.

Finally, it has been pointed out that the effect of wheel dampers should preferably be expressed in terms of their effects on the modal damping as well their success in eliminating squeal. Tests of rail dampers are rare and more data is needed on their success or otherwise.

There remain many difficulties to be overcome to arrive at a full understanding of curve squeal allowing its control in all situations. It is clear that to achieve this will involve aspects of vehicle dynamics, tribology and vibroacoustics and the various forms of curve squeal will only finally be solved and explained by suitable collaboration between these fields.

\section{References}

1. Anderson, D., Wheatley, N., Fogarty, B., Jiang, J., Howie, A., Potter, W.: Mitigation of curve squeal noise in Queensland, New South Wales and South Australia. In: Conference on Railway Engineering. pp. 625-636, Perth, Australia (2008)

2. Hanson, D., Jiang, J., Dowdell, B., \& Dwight, R.: Curve squeal: causes, treatments and results. In INTER-NOISE and NOISE-CON Congress and Conference Proceedings, vol. 249, pp. 6316-6323, Melbourne, Australia (2014)

3. Rudd, M. J.: Wheel/rail noise-Part II: Wheel squeal. Journal of Sound and Vibration 46(3), 381-394 (1976)

4. Remington, P. J.: Wheel/rail squeal and impact noise: What do we know? What don't we know? Where do we go from here? Journal of Sound and Vibration 116(2), 339-353 (1987)

5. Remington, P. J.: Wheel/rail rolling noise: What do we know? What don't we know? Where do we go from here? Journal of Sound and Vibration 120(2), 203-226 (1988)

6. Wickens, A. H.: Fundamentals of Rail Vehicle Dynamics, Guidance and Stability. Swets \& Zeitlinger, Lisse, (2003)

7. Thompson, D. J.: Railway Noise and Vibration: Mechanisms, Modelling and Mitigation. Elsevier: Oxford, (2009)

8. Kalker, J. J.: Three dimensional elastic bodies in rolling contact. Kluwer academic publishers, Dordrecht, (1990)

9. Vermeulen, P. J., Johnson, K. L.: Contact of nonspherical elastic bodies transmitting tangential forces. Journal of Applied Mechanics 31(2), 338-340 (1964)

10. Shen, Z. Y., Hedrick, J. K., Elkins, J. A.: A comparison of alternative creep-force models for rail vehicle dynamic analysis. Proceedings of 8th IAVSD Symposium, Cambridge MA, Swets and Zeitlinger, Lisse, pp. 591-605, 1983

11. Huang, Z. Y.: Theoretical Modelling of Railway Curve Squeal. PhD thesis, University of Southampton, UK, 2007

12. Hoffmann, N., Fischer, M., Allgaier, R., Gaul, L.: A minimal model for studying properties of the mode-coupling type instability in friction induced oscillations. Mechanics Research Communications 29(4), 197-205 (2002)

13. Hoffmann, N., Gaul, L.: Effects of damping on mode-coupling instability in friction induced oscillations. Journal of Applied Mathematics and Mechanics 83(8), 524-534 (2003)

14. Sinou, J. J., Jezequel, L.: Mode coupling instability in friction-induced vibrations and its dependency on system parameters including damping. European Journal of Mechanics-A/Solids 26(1), 106-122 (2007)

15. Johnson. K. L.: Contact Mechanics, Cambridge University Press, Cambridge, (1985)

16. Kinkaid, N. M., O'Reilly, O. M., Papadopoulos, P.: Automotive disc brake squeal. Journal of Sound and Vibration 267(1), 105-166 (2003) 
17. Ghazaly, N. M., El-Sharkawy, M., Ahmed, I.: A review of automotive brake squeal mechanisms. Journal of Mechanical Design and Vibration 1(1), 5-9 (2013)

18. Ouyang, H., Nack, W., Yuan, Y., Chen, F.: Numerical analysis of automotive disc brake squeal: a review. International Journal of Vehicle Noise and Vibration 1(3-4), 207-231 (2005)

19. Dorf, R. C., Bishop, R. H.: Modern control systems (11 ${ }^{\text {th }}$ edition). Prentice Hall. (2008).

20. De Beer, F. G., Janssens, M. H. A., Kooijman, P. P., van Vliet, W. J.: Curve squeal of railbound vehicles (part 1): frequency domain calculation model. In: Proceedings of Internoise, vol 3, pp. 15601563, Nice, France (2000)

21. Von Stappenbeck, H.: Das Kurvengeräusch der Straßenbahn. Möglichkeiten zu seiner Unterdrückung. Zeitschrift VDI 96(6), 171-175 (1954)

22. Van Ruiten, C. J. M.: Mechanism of squeal noise generated by trams. Journal of Sound and Vibration 120(2), 245-253 (1988)

23. Nakai, M., Chiba, Y., Yokoi, M.: Railway wheel squeal: 1st report, on frequency of squeal, Bulletin of The Japan Society of Mechanical Engineers 25, 1127-1134 (1982)

24. Nakai, M., Chiba, Y., Yokoi, M.: Railway wheel squeal: 2nd report, mechanism of specific squeal frequency, Bulletin of The Japan Society of Mechanical Engineers 27, 301-308 (1984)

25. Nakai, M., Chiba, Y., Yokoi, M.: Railway wheel squeal: 3rd report, squeal of a disk simulating a wheel in internal resonances, Bulletin of The Japan Society of Mechanical Engineers 28, 500-507 (1985)

26. Schneider, E., Popp, K., Irretier, H.: Noise generation in railway wheels due to rail-wheel contact forces. Journal of Sound and Vibration 120(2), 227-244 (1988)

27. Kraft, K.: Der Einfluß der Fahrgeschwindigkeit auf den Haftwert zwischen Rad und Schiene. Archiv für Eisenbahntechnik 22, 58-78 (1967)

28. Fingberg, U.: A model of wheel-rail squealing noise. Journal of Sound and Vibration 143(3), 365-377 (1990)

29. Périard, F. Wheel-Rail Noise Generation: Curve Squealing by Trams. PhD thesis, Technische Universiteit Delft, (1998)

30. Heckl, M. A., Abrahams, I. D.: Curve squeal of train wheels, part 1: mathematical model for its generation. Journal of Sound and Vibration 229(3), 669-693 (2000)

31. Heckl, M. A.: Curve squeal of train wheels, Part 2: Which wheel modes are prone to squeal? Journal of Sound and Vibration 229(3), 695-707 (2000)

32. Heckl, M. A.: Curve squeal of train wheels: unstable modes and limit cycles. In: Proceedings of the Royal Society of London A: Mathematical, Physical and Engineering Sciences, vol. 458, pp. 19491965. (2002)

33. Liu, X., Meehan, P. A.: Wheel squeal noise: A simplified model to simulate the effect of rolling speed and angle of attack. Journal of Sound and Vibration 338, 184-198 (2015)

34. Meehan, P. A., Liu, X.: Analytical prediction and investigation of wheel squeal amplitude. In Anderson, D., et al. (eds.) Noise and Vibration Mitigation for Rail Transportation Systems. NNFM, vol. 139, pp 69-80. Springer, Heidelberg (2018)

35. Kooijman, P. P., Van Vliet, W. J., Janssens, M. H. A., De Beer, F. G.: Curve squeal of railbound vehicles (part 2): set-up for measurement of creepage dependent friction coefficient. In: Proceedings of Internoise, vol 3, pp. 1564-1567, Nice, France (2000)

36. De Beer, F. G., Janssens, M. H. A., Kooijman, P. P.: Squeal noise of rail-bound vehicles influenced by lateral contact position. Journal of Sound and Vibration 267(3), 497-507 (2003)

37. Thompson, D. J., Hemsworth, B., Vincent, N.: Experimental validation of the TWINS prediction program for rolling noise, part 1: description of the model and method. Journal of sound and vibration 193(1), 123-135 (1996)

38. Monk-Steel, A., Thompson, D. J.: Models for railway curve squeal noise. In: VIII International Conference on Recent Advances in Structural Dynamics, Southampton, UK, 2003

39. Barman, J. F., Katzenelson, J.: A generalized Nyquist-type stability criterion for multivariable feedback systems. International Journal of Control 20(4), 593-622 (1974) 
40. Huang, Z. Y., Thompson, D. J., Jones, C. J. C.: Squeal prediction for a bogied vehicle in a curve. In Schulte-Werning, B., et al. (eds.) Noise and Vibration Mitigation for Rail Transportation Systems. NNFM vol. 99, pp. 313-319. Springer, Heidelberg (2008)

41. Hsu, S. S., Huang, Z., Iwnicki, S. D., Thompson, D. J., Jones, C. J., Xie, G., Allen, P. D.: Experimental and theoretical investigation of railway wheel squeal. Proceedings of the Institution of Mechanical Engineers, Part F: Journal of Rail and Rapid Transit 221(1), 59-73 (2007)

42. Squicciarini, G., Usberti, S., Thompson, D. J., Corradi, R., Barbera, A.: Curve squeal in the presence of two wheel/rail contact points. In Nielsen, J.C.O., et al. (eds.) Noise and Vibration Mitigation for Rail Transportation Systems. NNFM, vol. 126, pp. 603-610. Springer, Heidelberg (2015)

43. Xie, G., Allen, P. D., Iwnicki, S. D., Alonso, A., Thompson, D. J., Jones, C. J., Huang, Z. Y.: Introduction of falling friction coefficients into curving calculations for studying curve squeal noise. Vehicle System Dynamics 44(sup1), 261-271 (2006)

44. Giménez, J. G., Alonso, A., Gómez, E.: Introduction of a friction coefficient dependent on the slip in the FastSim algorithm. Vehicle System Dynamics 43(4), 233-244 (2005)

45. Chiello, O., Ayasse, J. B., Vincent, N., Koch, J. R.: Curve squeal of urban rolling stock-Part 3: Theoretical model. Journal of Sound and Vibration 293(3), 710-727 (2006)

46. Collette, C.: Importance of the wheel vertical dynamics in the squeal noise mechanism on a scaled test bench. Shock and Vibration 19(2), 145-153 (2012)

47. Brunel, J. F., Dufrénoy, P., Naït, M., Muñoz, J. L., Demilly, F.: Transient models for curve squeal noise. Journal of sound and vibration 293(3), 758-765 (2006)

48. Glocker, C., Cataldi-Spinola, E., Leine, R. I.: Curve squealing of trains: Measurement, modelling and simulation. Journal of Sound and Vibration 324(1), 365-386 (2009)

49. Pieringer A.: A numerical investigation of curve squeal in the case of constant wheel/rail friction. Journal of Sound and Vibration 333(18), 4295-4313 (2014)

50. Pieringer, A., Kropp, W.: A time-domain model for coupled vertical and tangential wheel/rail interaction - a contribution to the modelling of curve squeal. In Maeda, T., et al. (eds.) Noise and Vibration Mitigation for Rail Transportation Systems. NNFM, vol. 118, pp. 221-229, Springer, Heidelberg (2012)

51. Pieringer, A., Baeza, L., Kropp. W.: Modelling of railway curve squeal including effects of wheel rotation. In Nielsen, J.C.O., et al. (eds.) Noise and Vibration Mitigation for Rail Transportation Systems. NNFM, vol. 126, pp. 417-424, Springer, Heidelberg (2015)

52. Zenzerovic, I., Pieringer, A., Kropp. W.: Towards an engineering model for curve squeal. In Nielsen, J.C.O., et al. (eds.) Noise and Vibration Mitigation for Rail Transportation Systems. NNFM, vol. 126, pp. 433-440, Springer, Heidelberg (2015)

53. Zenzerovic, I., Kropp, W., Pieringer, A.: An engineering time-domain model for curve squeal: Tangential point-contact model and Green's functions approach. Journal of Sound and Vibration 376, 149-165 (2016)

54. Pieringer, A., Torstensson, P. T., Giner, J., Baeza, L.: Investigation of railway curve squeal using a combination of frequency- and time-domain models. In Anderson, D., et al. (eds.) Noise and Vibration Mitigation for Rail Transportation Systems. NNFM, vol. 139, pp 81-93. Springer, Heidelberg (2018)

55. Chen, G. X., Xiao, J. B., Liu, Q. Y., Zhou. Z. R.: Complex eigenvalue analysis of railway curve squeal. In Schulte-Werning, B., et al. (eds.) Noise and Vibration Mitigation for Rail Transportation Systems. NNFM, vol. 99, pp. 433-439, Springer, Heidelberg (2008)

56. Fourie, D.J., Gräbe, P.J., Heyns, P.S., Fröhling, R.D.: Analysis of wheel squeal due to unsteady longitudinal creepage using the complex eigenvalue method. In Anderson, D., et al. (eds.) Noise and Vibration Mitigation for Rail Transportation Systems. NNFM, vol. 139, pp 55-67. Springer, Heidelberg (2018)

57. Wang, C., Dwight, R., Li, W., Jiang, J.: Prediction on curve squeal in the case of constant wheel rail friction coefficient. In Anderson, D., et al. (eds.) Noise and Vibration Mitigation for Rail Transportation Systems. NNFM, vol. 139, pp XXX-XXX. Springer, Heidelberg (2018) 
58. Ding, B., Squicciarini, G., Thompson, D. J.: Effects of rail dynamics and friction characteristics on curve squeal. In: XIII International Conference on Motion and Vibration Control and XII International Conference on Recent Advances in Structural Dynamics (MoViC/RASD), Southampton, (2016)

59. Bleedorn, T. G., Johnstone. B.: Steerable steel wheel systems and wheel noise suppression. In: Conf Rec IAS 12th Annual Meeting, Los Angeles, California, (1977)

60. Koch, J. R., Vincent, N., Chollet, H., Chiello, O.: Curve squeal of urban rolling stock-Part 2: Parametric study on a 1/4 scale test rig. Journal of sound and vibration 293(3), 701-709 (2006)

61. Logston, C. F., Itami, G. S.: Locomotive friction-creep studies. ASME Journal of Engineering for Industry 102(3), 275-281 (1980).

62. Ertz, M.: Creep force laws for wheel/rail contact with temperature-dependent coefficient of friction. In: 8th Mini Conf. on Vehicle System Dynamics, Identification and Anomalies, Budapest, (2002)

63. Lang, W., Roth, R.: Optimale Kraftschlussausnutzung bei Hochleistungs-Schienenfahrzeugen, Eisenbahntechnische Rundschau 42, 61-66 (1993).

64. Polach, O.: Creep forces in simulations of traction vehicles running on adhesion limit. Wear 258(7), 992-1000 (2005)

65. Zhang, W., Chen, J., Wu, X., Jin, X.: Wheel/rail adhesion and analysis by using full scale roller rig. Wear 253(1), 82-88 (2002)

66. Harrison, H., McCanney, T., Cotter, J.: Recent developments in coefficient of friction measurements at the rail/wheel interface. Wear 253(1), 114-123 (2002)

67. Gallardo-Hernandez, E. A., Lewis, R.: Twin disc assessment of wheel/rail adhesion. Wear 265(9), 1309-1316 (2008)

68. Fletcher, D. I., Lewis, S.: Creep curve measurement to support wear and adhesion modelling, using a continuously variable creep twin disc machine, Wear 298-299, 57-65 (2013)

69. Fletcher, D. I.: A new two-dimensional model of rolling-sliding contact creep curves for a range of lubrication types. Proceedings of the Institution of Mechanical Engineers, Part J: Journal of Engineering Tribology 227(6), 529-537 (2013)

70. Matsumoto, A., Sato, Y., Ono, H., Wang, Y., Yamamoto, M., Tanimoto, M., Oka, Y.: Creep force characteristics between rail and wheel on scaled model. Wear 253(1), 199-203 (2002)

71. Janssens, M. H. A., van Vliet, W. J., Kooijman, P. P., De Beer, F. G.: Curve squeal of railbound vehicles (part 3): measurement method and results. In: Proceedings of Internoise, vol 3, pp.1568-1571, Nice, France (2000)

72. Monk-Steel, A. D., Thompson, D. J., De Beer, F. G., Janssens, M. H. A.: An investigation into the influence of longitudinal creepage on railway squeal noise due to lateral creepage. Journal of Sound and Vibration 293(3), 766-776 (2006)

73. Liu, X., Meehan, P. A.: Investigation of the effect of lateral adhesion and rolling speed on wheel squeal noise. Proceedings of the Institution of Mechanical Engineers, Part F: Journal of Rail and Rapid Transit 227(5), 469-480 (2013)

74. Liu, X., Meehan, P. A.: Investigation of the effect of relative humidity on lateral force in rolling contact and curve squeal. Wear 310(1), 12-19 (2014)

75. Liu, X., Meehan, P. A.: Investigation of squeal noise under positive friction characteristics condition provided by friction modifiers. Journal of Sound and Vibration 371, 393-405 (2016)

76. Jie, E., Kim, J. Y., Hwang, D. H., Lee, J. H., Kim, K. J., Kim, J. C.: An experimental study of squeal noise characteristics for railways using a scale model test rig. In: J. Pombo (Ed.) Proceedings of the Third International Conference on Railway Technology: Research, Development and Maintenance, Cagliari, Sardinia, Italy (2016)

77. Eadie, D. T., Santoro, M., Kalousek, J.: Railway noise and the effect of top of rail liquid friction modifiers: changes in sound and vibration spectral distributions in curves. Wear 258(7), 1148-1155 (2005)

78. Bullen, R., Jiang, J.: Algorithms for detection of rail wheel squeal. In: 20th International Congress on Acoustics 2010, ICA 2010 - Incorporating Proceedings of the 2010 Annual Conference of the Australian Acoustical Society. pp. 2212-2216 (2010) 
79. Stefanelli, R., Dual, J., Cataldi-Spinola, E.: Acoustic modelling of railway wheels and acoustic measurements to determine involved eigenmodes in the curve squealing phenomenon. Vehicle System Dynamics 44(sup1), 286-295 (2006)

80. Vincent, N., Koch, J. R., Chollet, H., Guerder, J. Y.: Curve squeal of urban rolling stock—Part 1: State of the art and field measurements. Journal of Sound and Vibration 293(3), 691-700 (2006)

81. Anderson, D., Wheatley, N.: Mitigation of wheel squeal and flanging noise on the Australian network. In Schulte-Werning, B., et al. (eds.) Noise and Vibration Mitigation for Rail Transportation Systems. NNFM, vol. 99, pp.399-405, Springer, Heidelberg (2008)

82. Curley, D., Anderson, D. C., Jiang, J., Hanson, D.: Field trials of gauge face lubrication and top-of-rail friction modification for curve noise mitigation. . In Nielsen, J.C.O., et al. (eds.) Noise and Vibration Mitigation for Rail Transportation Systems. NNFM, vol. 126, pp. 449-456. Springer, Heidelberg (2015)

83. Jiang, J., Hanson, D., Dowdell, B.: Wheel squeal - insights from wayside condition monitoring measurements and field trials. In Anderson, D., et al. (eds.) Noise and Vibration Mitigation for Rail Transportation Systems. NNFM, vol. 139, pp 41-53. Springer, Heidelberg (2018)

84. Jiang, J., Dwight, R., Anderson, D.: Field verification of curving noise mechanisms. In Maeda, T., et al. (eds.) Noise and Vibration Mitigation for Rail Transportation Systems. NNFM, vol. 118, pp. 349-356, Springer, Heidelberg (2012)

85. Jiang, J., Anderson, D. C., Dwight, R.: The mechanisms of curve squeal. In Nielsen, J.C.O., et al. (eds.) Noise and Vibration Mitigation for Rail Transportation Systems. NNFM, vol. 126, pp. 587-594. Springer, Heidelberg (2015)

86. Fourie, D. J., Gräbe, P. J., Heyns, P. S., Fröhling, R. D.: Experimental characterisation of railway wheel squeal occurring in large-radius curves. Proceedings of the Institution of Mechanical Engineers, Part F: Journal of Rail and Rapid Transit, 230(6) 1561-1574 (2016)

87. Corradi, R., Crosio, P., Manzoni, S., Squicciarini, G.: Experimental investigation on squeal noise in tramway sharp curves. In: Proceedings of the 8th International Conference on Structural Dynamics, EURODYN 2011, Leuven, 2011

88. Merideno, I., Nieto, J., Gil-Negrete, N., Landaberea, A., Iartza, J.: Constrained layer damper modelling and performance evaluation for eliminating squeal noise in trams. Shock and Vibration, (2014)

89. Nelson J. T.: Wheel/rail noise control manual, TCRP Report 23, (1997)

90. Krüger, F.: Schall- und Erschütterungsschutz im Schienenverkehr, Expert Verlag, Renningen, (2001)

91. Elbers, F., Verheijen, E.: Railway noise technical measures catalogue, UIC report UIC003-01-04fe, (2013)

92. Oertli, J.: Combatting curve squeal, phase II, final report, UIC (2005)

93. Eadie, D. T., Santoro, M., Powell, W.: Local control of noise and vibration with KELTRACK ${ }^{\mathrm{TM}}$ friction modifier and Protector® trackside application: an integrated solution. Journal of Sound and Vibration 267(3), 761-772 (2003)

94. Eadie, D. T., Santoro, M.: Top-of-rail friction control for curve noise mitigation and corrugation rate reduction. Journal of Sound and Vibration 293(3), 747-757 (2006).

95. Suda, Y., Iwasa, T., Komine, H., Tomeoka, M., Nakazawa, H., Matsumoto, K., Nakai, T., Tanimoto, M., Kishimoto, Y.: Development of onboard friction control. Wear 258(7), 1109-1114 (2005)

96. Bühler, S., Thallemer, B.: How to avoid squeal noise on railways: state of the art and practical experience. In Schulte-Werning, B., et al. (eds.) Noise and Vibration Mitigation for Rail Transportation Systems. NNFM, vol. 99, pp. 406-411. Springer, Heidelberg (2008)

97. Jones, C. J. C., Thompson, D. J.: Rolling noise generated by railway wheels with visco-elastic layers. Journal of Sound and Vibration 231(3), 779-790 (2000)

98. Wetta, P., Demilly, F.: Reduction of wheel squeal noise generated on curves or during braking. In 11th International of Wheelset Congress, Paris, (1995)

99. Brunel, J. F., Dufrénoy, P., Demilly, F.: Modelling of squeal noise attenuation of ring damped wheels. Applied Acoustics 65(5), 457-471 (2004) 
100.Marjani, S. R., Younesian, D.: Suppression of train wheel squeal noise by shunted piezoelectric elements. International Journal of Structural Stability and Dynamics, (2016)

101.Heckl, M.A., Huang, X.Y.: Curve squeal of train wheels, part 3: active control, Journal of Sound and Vibration 229(3), 709-735 (2000)

102.Thompson, D. J., Jones, C. J. C., Waters T. P., Farrington, D.: A tuned damping device for reducing noise from railway track. Applied Acoustics 68(1), 43-57 (2007).

103.Jiang, J., Ying, I., Hanson, D., Anderson, D. C.: An investigation of the influence of track dynamics on curve noise. In Nielsen, J.C.O., et al. (eds.) Noise and Vibration Mitigation for Rail Transportation Systems. NNFM, vol. 126, pp. 441-448, Springer, Heidelberg (2015)

104.Toward, M., Squicciarini, G., Thompson, D. J.: Reducing freight wagon noise at source. International Railway Journal. March, 47-49 (2015)

105.Illingworth, R., Pollard, M. G.: The use of steering axle suspensions to reduce wheel and rail wear in curves. Proceedings of the Institution of Mechanical Engineers 196(1), 379-385 (1982)

106.Garcia, J. F., Olaizola, X., Martin L. M., Gimenez, J.G.: Theoretical comparison between different configurations of radial and conventional bogies. Vehicle System Dynamics 33(4), 233-259 (2000)

107.Bruni, S., Goodall, R., Mei, T. X., Tsunashima, H.: Control and monitoring for railway vehicle dynamics. Vehicle System Dynamics 45(7-8), 743-779 (2007)

108.Hiensch, M., Larsson, P. O., Nilsson, O., Levy, D., Kapoor, A., Franklin, F., Nielsen, J., Ringsberg, J., Josefson, L.: Two-material rail development: field test results regarding rolling contact fatigue and squeal noise behaviour. Wear 258(7), 964-972 (2005)

109.Kopp, E.: Fünf Jahre Erfahrungen mit asymmetrisch geschliffenen Schienenprofilen, Eisenbahn Technische Rundschau 40, 665 (1991) 